\title{
Star-shaped tetrathiafulvalene oligomers towards the construction of conducting supramolecular assembly
}

\author{
Masahiko lyoda ${ }^{* 1}$ and Masashi Hasegawa ${ }^{2}$
}

\author{
Review \\ Address: \\ ${ }^{1}$ Department of Chemistry, Graduate School of Science and \\ Engineering, Tokyo Metropolitan University, Hachioji, Tokyo \\ 192-0397, Japan and 2Department of Chemistry, School of Science, \\ Kitasato University, 1-15-1 Kitasato, Minami-ku, Sagamihara, \\ Kanagawa 252-0373, Japan \\ Email: \\ Masahiko lyoda* - iyoda@tmu.ac.jp \\ * Corresponding author \\ Keywords: \\ conducting fibers; star-shaped molecules; supramolecular assembly; \\ tetrathiafulvalene oligomers
}

Beilstein J. Org. Chem. 2015, 11, 1596-1613.

doi:10.3762/bjoc. 11.175

Received: 15 June 2015

Accepted: 20 August 2015

Published: 10 September 2015

This article is part of the Thematic Series "Tetrathiafulvalene chemistry".

Guest Editor: P. J. Skabara

(C) 2015 lyoda and Hasegawa; licensee Beilstein-Institut. License and terms: see end of document.

\begin{abstract}
The construction of redox-active supramolecular assemblies based on star-shaped and radially expanded tetrathiafulvalene (TTF) oligomers with divergent and extended conjugation is summarized. Star-shaped TTF oligomers easily self-aggregate with a nanophase separation to produce supramolecular structures, and their TTF units stack face-to-face to form columnar structures using the fastener effect. Based on redox-active self-organizing supramolecular structures, conducting nanoobjects are constructed by doping of TTF oligomers with oxidants after the formation of such nanostructures. Although radical cations derived from TTF oligomers strongly interact in solution to produce a mixed-valence dimer and $\pi$-dimer, it seems to be difficult to produce nanoobjects of radical cations different from those of neutral TTF oligomers. In some cases, however, radical cations form nanostructured fibers and rods by controlling the supramolecular assembly, oxidation states, and counter anions employed.
\end{abstract}

\section{Introduction}

Tetrathiafulvalene (TTF) chemistry first attracted enthusiastic attention of chemists and physicists on high electrical conductivity and superconductivity with high $T_{\mathrm{c}}$ temperature. Recently, however, TTF and its derivatives are frequently employed as a redox-active moiety for organic electronic devices such as fieldeffect-transistors (FET), dye-sensitized solar cells (DSC), positive electrode materials for rechargeable batteries, and electrochromic (EC) materials [1].
TTF derivatives are versatile building blocks to form aggregates in the solid state with interesting conducting and magnetic behavior [2]. Although these properties are mainly originated from specific interactions between molecules having one or more unpaired electrons $[3,4]$, neutral TTF and its derivatives also easily form stacked columnar structures with face-to-face $\pi \cdots \pi$ stacking and side-by-side $\mathrm{S} \cdots \mathrm{S}$ interactions in the crystalline state. Furthermore, weak intermolecular interactions 
(hydrogen bonding, metal coordination, CT interaction, $\pi \cdots \pi$ stacking, van der Waals interaction, etc.) play an important role in the formation of the three-dimensional (3D) crystal structures [5]. For the construction of nanostructured objects, $\pi \cdots \pi$, $\mathrm{S} \cdots \mathrm{S}$, and other weak intermolecular interactions first accelerate self-aggregation of molecules in solution [6-8] and then produce the functional one-dimensional (1D) or two-dimensional (2D) supramolecular structures, which are very important in advanced nanosciences [9-11]. For the formation of the nanostructured objects such as fibers, rods, tubes, and particles, amphiphilic TTFs having a rigid core and long alkyl chains are one of the best molecular systems. The self-assembly of TTF derivatives in solid and on surface gives rise to a long-distance dynamic ordering as compared with single crystals.

Among the recent researches on TTF and its derivatives, radially expanded or star-shaped multi-TTFs with $C_{3}$ and $C_{6}$ symmetries have attracted considerable attention in the field of materials science because of their divergent and extended $\pi$-conjugation. Various $C_{3}$-symmetric compounds incorporating three conjugated TTF units were designed and synthesized to realize TTF-based conducting organic magnets using ferromagnetic interaction between the two TTF radical cations [12-21]. On the other hand, compounds with a hexagonal molecular symmetry were used as core structures for constructing conductive fibers and functional dyes [22,23]. Furthermore, various multifunctional TTF-based supramolecular architectures have been designed and synthesized to realize molecular sensors, redox switches, multi-input systems for logic gates, electrochemically-driven conformational controls, molecular clips and tweezers, and redox-controlled gelation processes. TTF-based supramolecular chemistry in solution was thoroughly outlined in recent reviews of Jeppesen, Nielsen, and Becher (2004) [24], Iyoda, Hasegawa, and Miyake (2004) [25,26], Sallé and Zhang (2009) [27], and Martin $(2009,2012)$ $[28,29]$. However, limited examples of redox-active nanostructures in the solid state were summarized so far. Therefore, this review focuses on the conducting nanostructures of TTF derivatives in the solid state, together with association behavior in solution.

\section{Review}

\section{Redox-active radially expanded TTF oligomers in solution and the solid state}

TTF oligomers with radially expanded structures can be expected to demonstrate multifunctional properties because a central core and TTF branches exhibit individual and/or cooperative functionalities [25]. For example, dendrimers composed of central benzenoid cores and TTF branches are cited as representative examples [30-33]. Other functional units such as fullerenes [34,35], cyclodextrins [36], porphyrin [37], and phthalocyanine [38-40] can also be introduced into the core of radial oligo-TTFs. As shown in Figure 1, TTF-annelated porphyrin 1 was synthesized by Becher and co-workers in 2001 [37]. Reflecting its strong $\pi$-donor ability, 1 was oxidized spontaneously in solution to afford $\mathbf{1}^{\mathbf{}}+$ under ambient conditions. Multifunctional TTF-crown ether-substituted phthalocyanine (Pc) 2a and its copper(II) complex $\mathbf{2 b}$ were reported by Amabilino, Rowan, Nolte, and co-workers in 2005 [40]. The giant molecule 2a self-aggregated in chloroform-dioxane to form a gel. TEM images of the xerogel exhibited helical molecular tapes nanometer wide and micrometer long. A cyclic voltammetry (CV) study on $\mathbf{2} \mathbf{b}$ showed the redox properties expected for Pc and TTF, and doping of $\mathbf{2 b}$ in $\mathrm{CH}_{2} \mathrm{Cl}_{2}$ with $\mathrm{I}_{2}$ produced a radical cation species.

Among radially expanded TTFs, Jeppesen, Becher, Nielsen, Sessler, and co-workers reported TTF-calix[4]pyrrole 3 as a valuable supramolecular receptor, and $\mathbf{3}$ easily incorporated 1,3,5-trinitrobenzene (TNB) in the cavity to form 4 $(3: \mathrm{TNB}=1: 2)$ (Figure 2) $[41,42]$. Furthermore, in the presence of halide ions, 3 formed the $\mathrm{C}_{60}$ complex $\mathbf{5}$, in which $\mathrm{C}_{60}$ was bound within the bowl-like cup of the TTF-calix[4]pyrrole core in a ball-and-socket binding mode [43].

Recently, the $C_{3}$-symmetric compounds $\mathbf{6 a}, \mathbf{b}$ incorporating three TTF residues were reported by Amabilino, Avarvari, and co-workers (Figure 3) [21]. The three TTF units with chiral citronellyl and dihydrocitronellyl chains led to helical onedimensional stacks in solution to produce fibers that have morphologies depending on the nature of the chiral alkyl group, although an achiral counterpart showed no helicity. $C_{3}$-symmetric truxene-TTFs $7 \mathbf{a}-\mathbf{c}$ were synthesized by Ortí, Martín, and co-workers (Figure 3) [44].

The pioneering studies on the synthesis of tetrakis(1,3-dithiol-2ylidene)cyclobutane (8) and related [5] and [6]radialenes 9 and 10a,b were reported by Yoshida and co-workers in the 1980's (Figure 4). These $\pi$-expanded TTFs 8-10a,b exhibited unique $\mathrm{X}$-ray structures and multi-redox behavior [45-47].

\section{Conducting supramolecular assembly of oligo-TTFs}

The electric conductivities of doped nanofibers and nanorods derived from TTF and its derivatives are measured by mounting them on $\mathrm{Au}$ electrodes with a $\mu \mathrm{m}$-sized spacing. On the other hand, the conductivities of the corresponding neutral nanoobjects are determined by pulse-radiolysis or flash-photolysis time-resolved microwave conductivity techniques $[48,49]$. Current-sensing atomic force microscopy (CS-AFM) and combination of scanning tunneling microscopy and spectroscopy (STM/STS) are also employed for determining the 

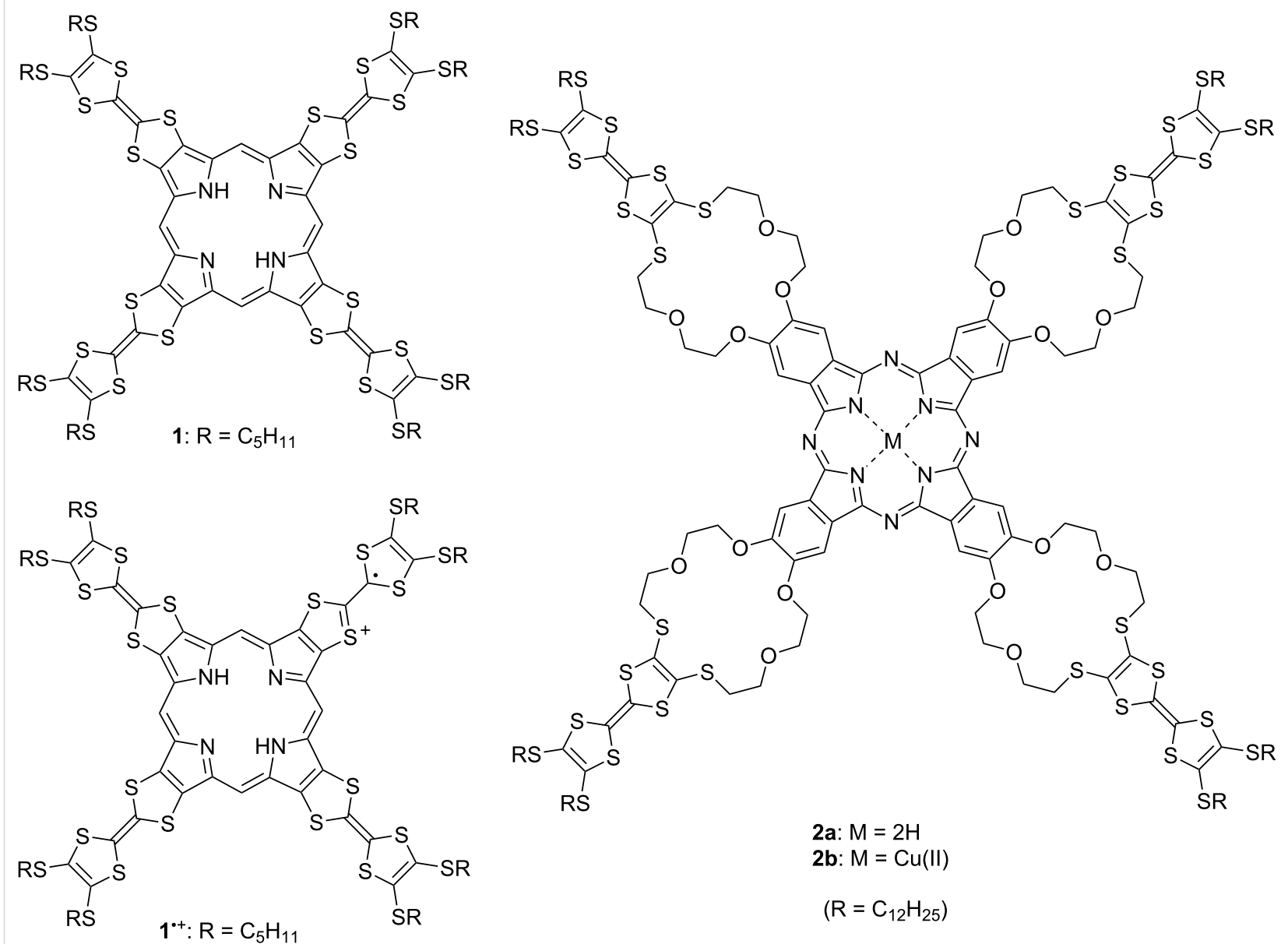

2a: $M=2 H$

2b: $\mathrm{M}=\mathrm{Cu}(\mathrm{II})$

$\left(\mathrm{R}=\mathrm{C}_{12} \mathrm{H}_{25}\right)$

Figure 1: Radially expanded TTF oligomers 1 and 2 a,b
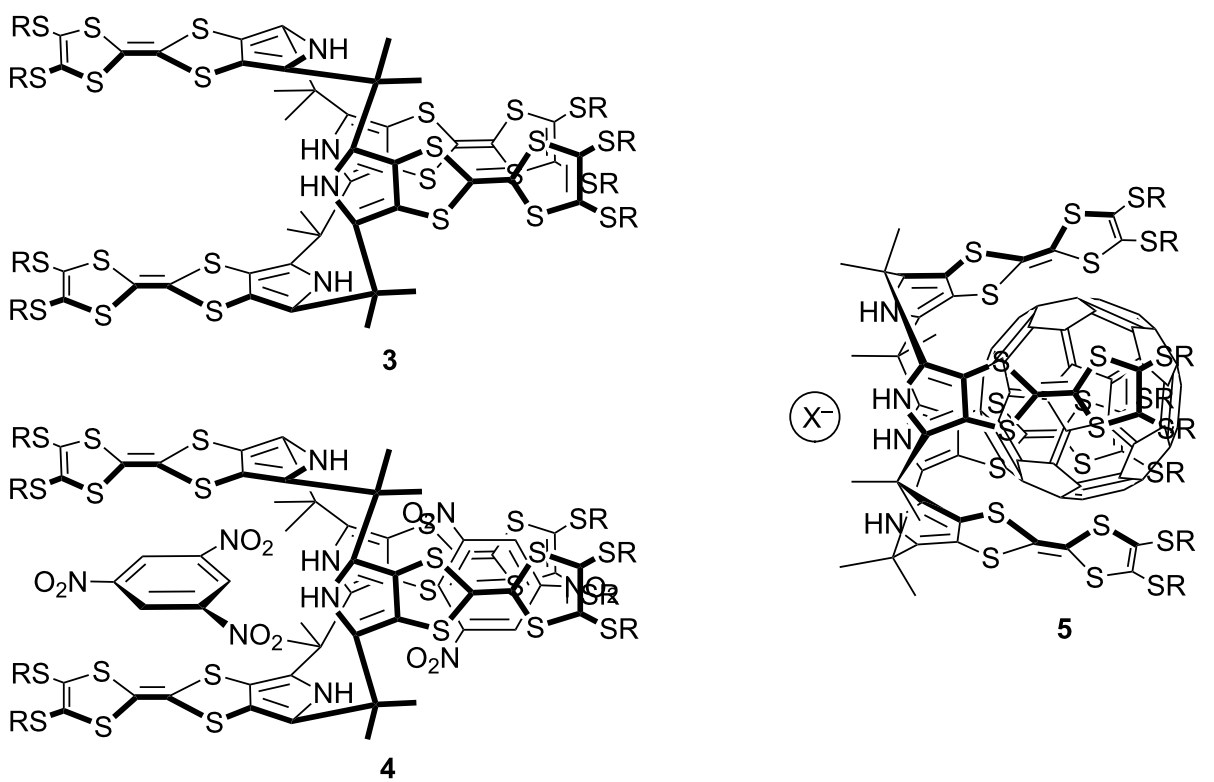

Figure 2: TTF-calix[4]pyrrole 3 and its TNT and $\mathrm{C}_{60}$ complexes 4 and 5 
<smiles>[R5]C1=C([R5])SC(=C2SC=C(C(=O)Nc3ccccc3-c3ncccc3NC(=O)c3cc(C(=O)Nc4cccnc4-c4ncccc4NC(=O)C4=CSC(=C5SC([R5])=C([R5])S5)S4)cc(C(=O)Nc4cccnc4-c4ncccc4NC(=O)C4=CSC(=C5SC([R5])=C([R5])S5)S4)c3)S2)S1</smiles><smiles></smiles>

7a: $\mathrm{R}=\mathrm{H}$

7b: $\mathrm{R}=\mathrm{SMe}$

7c: $\mathrm{R}=\left(\mathrm{SCH}_{2}\right)_{2}$

Figure 3: $C_{3}$-symmetric TTF derivatives $6 \mathbf{a}, \mathbf{b}$ and $7 \mathbf{a}-\mathbf{c}$.<smiles></smiles>

8<smiles>c1ccc2c(c1)SC(=C1C(=C3Sc4ccccc4S3)C(=C3Sc4ccccc4S3)C(=C3Sc4ccccc4S3)C1=C1Sc3ccccc3S1)S2</smiles>

9<smiles>[R]C1=C([R])SC(=c2c(=C3SC([R])=C([R])S3)c(=C3SC([R])=C([R])S3)c(=C3SC([R])=C([R])S3)c(=C3SC([R])=C([R])S3)c2=C2SC([R])=C([R])S2)S1</smiles>

10a: $\mathrm{R}=\mathrm{COOMe}$

10b: $\mathrm{R}=-(\mathrm{CH}=\mathrm{CH})_{2}-$

Figure 4: Radially expanded TTF derivatives 8, 9, and 10a,b.

conductivities of nanoobjects [50,51]. The electrical conductivity of nanostructures mainly depends on the alignment of stacked TTFs or their radical salts. The first fibrous material was fabricated by using arborol-TTF 11 in 1994 by Joergensen, Bechgaard, and co-workers (Figure 5) [52]. Although 11 showed no conductivity, Bryce and co-workers synthesized arborol-functionalized TTF derivative $\mathbf{1 2}$ in 2003, whose doped film exhibited a moderate level of conductivity $\left(\sigma_{\mathrm{rt}} \approx 10^{-4} \mathrm{~S} \mathrm{~cm}^{-1}\right)$ [53]. In 2005, several groups reported the formation of nanofibers using amphiphilic TTFs (13 and 14) (Figure 5) [54-56] After that, many research efforts have been focused on the construction of conducting nanoobjects possibly employed as nanosized electric wires, wirings, molecular switches, and devices. Some neutral nanoobjects derived from TTFs show electroconductivity owing to the fastener effect [57]; however, the oxidation of face-to-face stacked TTFs easily generates highly conducting states with unfilled band structure. Thus, the doping of neutral nanoobjects with iodine is generally used for preparing conducting nanostructures. Chemically oxidized TTFs in solution are also available for preparing conducting nanofibers.

The fastener effect [57], which enhances the face-to-face interaction between the two TTFs, can be used to construct conducting nanostructured fibers in the neutral state, and doping of the fibers with iodine affords black conducting fibers. For example, 
<smiles>[R][R7]=[R7]C=[R][R]</smiles><smiles>CCCCCCCCCCCCC(=O)NC(C(=O)COCC1=CSC(=C2SC=CS2)S1)C(C)C</smiles>

13

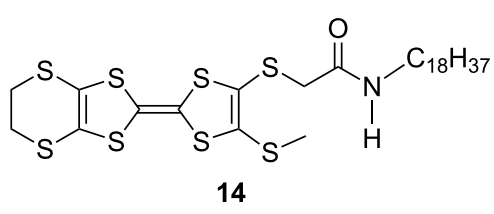<smiles>[R5]C1=C([R5])SC(=C2SC=C(C3=CSC(=C4SC([R5])=C([R])S4)S3)S2)S1</smiles>

15a: $\mathrm{R}=\mathrm{SC}_{12} \mathrm{H}_{25}$

15b: $R=H$

Figure 5: Amphiphilic TTFs 11-14 and 15a,b.

the bi-TTF derivative 15a with long alkylthio chains as substituents was synthesized (Figure 5) [58]. Bi-TTF 15a formed reddish orange rods which exhibited a bulk conductivity of $\sigma_{\mathrm{rt}}=1.0 \times 10^{-6} \mathrm{~S} \mathrm{~cm}^{-1}$ without doping. The p-type semiconductivity was detected by CS-AFM. Furthermore, the doping of 15a with iodine and bromine vapors afforded black conducting complexes $\left(\sigma_{\mathrm{rt}}=1.1 \times 10^{-4}\right.$ and $1.5 \times 10^{-4} \mathrm{~S} \mathrm{~cm}^{-1}$, respectively).

For conjugated TTF dimers linked by $\pi$-systems or chalcogen atoms, intramolecular through-bond and/or through-space interactions can be expected between two TTF parts. The intramolecular through-bond interaction between the two TTF parts linked in a head-to-tail manner is calculated to be weak in the ground state [25]. Thus, the conjugation of the two neutral TTF parts in 16-19 is weak (Figure 6) [59]. In the cyclic voltammetry (CV) measurements, tetraethylthio-bi-TTF 16 showed two one-electron and one two-electron redox waves (Table 1), while other TTF dimers of 17-19 exhibited only two two-electron reversible redox waves corresponding to TTF/ $\mathrm{TTF}^{\circ+}$ and $\mathrm{TTF}^{\bullet+} / \mathrm{TTF}^{2+}$ at a normal scan rate $\left(100 \mathrm{mV} \mathrm{s}^{-1}\right)$. As shown in Table 1, however, steady-state electronic spectra of $16^{\mathbf{}}, \mathbf{1 7}^{\mathbf{*}}$, and $\mathbf{1 8}^{\circ+}$ show intramolecular interaction between TTF and $\mathrm{TTF}^{\circ+}$, and the absorption maxima were observed at ca. 450 and $750 \mathrm{~nm}$, together with broad absorption of intramolecular CT interactions between two TTF units at 1400, 1300, $1200 \mathrm{~nm}$, respectively. The magnitude of these broad absorption bands is clearly affected by the distance between two TTFs, and TTF

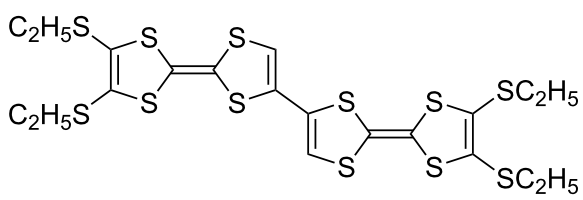

16

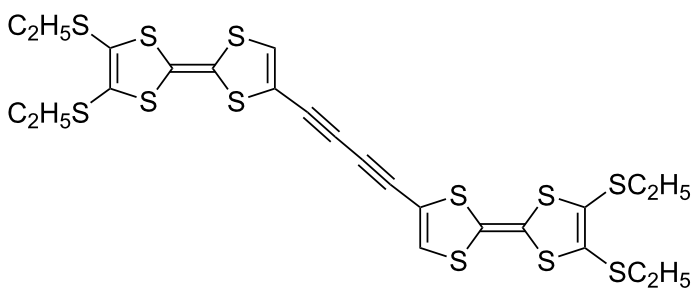

18

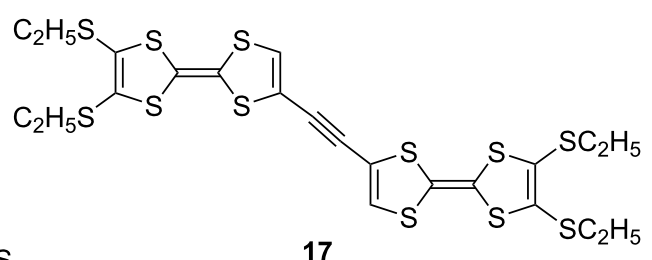

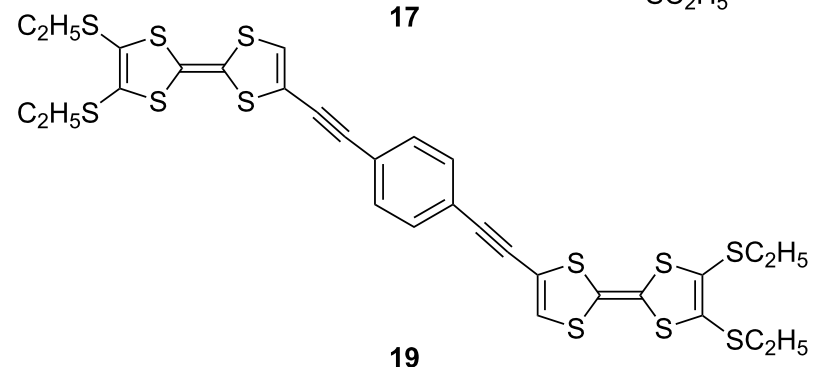

Figure 6: TTF dimers linked by $\sigma$-bond (16) and conjugated m-systems (17-19). 
Table 1: Redox potentials of $16-19$ and absorption maxima of monocations $16^{\circ+}, 17^{\circ+}, 18^{{ }^{+}}$and $19^{\circ+}$, and dications $16^{2+}, 17^{2+}, 18^{2+}$ and $19^{2+}[25,59]$

\begin{tabular}{llcclc} 
Compound & \multicolumn{2}{c}{ Redox potentials ${ }^{\mathrm{a}} \mathrm{vs} \mathrm{Fc} / \mathrm{Fc}^{+}$} & \multicolumn{2}{c}{ Absorption maxima } \\
& $E_{1 / 2}{ }^{\mathrm{b}}(\mathrm{V})$ & $E_{1 / 2}{ }^{2}(\mathrm{~V})$ & $E_{1 / 2}{ }^{3}(\mathrm{~V})$ & Monocation (nm) & Dication $(\mathrm{nm})$ \\
\hline 16 & 0.06 & 0.17 & 0.44 & $772,1400 \mathrm{br}$ & $816,1098 \mathrm{sh}$ \\
17 & 0.11 & 0.42 & & $778,1300 \mathrm{br}$ & 808 \\
18 & 0.12 & 0.42 & & $790,1200 \mathrm{br}$ & 804 \\
19 & 0.08 & 0.38 & & 790 & 796 \\
\hline
\end{tabular}

aPotentials were measured by cyclic voltammetry $(\mathrm{CV})$ in benzonitrile against a $\mathrm{Ag} / \mathrm{Ag}^{+}$electrode and adjusted to the $\mathrm{Fc} / \mathrm{Fc}^{+}$potential. ${ }^{\mathrm{b}} \mathrm{Measured}$ in $\mathrm{CH}_{2} \mathrm{Cl}_{2} / \mathrm{CH}_{3} \mathrm{CN}$ (4:1) using $\mathrm{Fe}\left(\mathrm{ClO}_{4}\right)_{3}$ as the oxidation reagent.

dimer $\mathbf{1 9}^{\cdot+}$ linked with a longer spacer exhibited no intramolecular CT absorption band. Moreover, the longest absorption maxima of the dications $16^{2+}, \mathbf{1 7}^{2+}$, and $\mathbf{1 8}^{2+}$ exhibit a bathochromic shift of 44,30 , and $14 \mathrm{~nm}$, respectively, from the

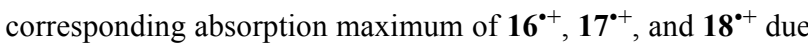
to the head-to-tail orientation of two $\mathrm{TTF}^{*+}$ (Davydov red shift) [25]. It is worth noting that the redox behavior of TTF dimers in $\mathrm{CV}$ measurements are sensitive to the concentration and the solvent used, and pristine bi-TTF $\mathbf{1 5 b}$ showed two reversible two-electron redox waves at -0.03 and $0.38 \mathrm{~V}$ vs $\mathrm{Fc} / \mathrm{Fc}^{+}$in benzonitrile under normal conditions $[25,60]$.

\section{Conducting nanostructure formation from star-shaped oligo-TTFs}

Although pristine TTF does not self-associate in solution due to the low association constant for dimerization, the mixedvalence (MV) dyad (TTF/TTF) ${ }^{\bullet+}$ and the dicationic dyad $\left(\mathrm{TTF}^{*+}\right)_{2}$, so-called $\pi$-dimer, are formed in concentrated solution or at low temperature [61]. On the other hand, the synergy of either the fastener effect or $\pi$-expansion allows star-shaped $C_{3}$-symmetric oligo-TTFs $\mathbf{2 2}$ and $\mathbf{2 3}$ to self-associate both in solution and in the solid state even in neutral state [18]. Compounds 22 and $\mathbf{2 3}$ were synthesized in good yields by Sonogashira coupling reaction of 1,3,5-triethynylbenzene with $\mathbf{2 0}$ and 1,3,5-triiodobenzene with 21, respectively (Scheme 1). $\mathrm{X}$-ray analysis of $\mathbf{2 2}$ revealed the columnar structure, in which the three TTF units stack in face-to-face manner to form single crystals (Figure 7).

In the case of $\mathbf{2 3}$ with butyl chains, this molecule dimerized in $\mathrm{CDCl}_{3}$ solution $\left(K_{2}=1.58 \pm 0.30 \mathrm{M}^{-1}\right.$ at $\left.293 \mathrm{~K}\right)$. The chemical shift of the central benzene ring clearly shifted higher field with an increase of concentration or lowering temperature. The observed shift is attributed to the shielding effect from the neighboring molecule that settles in face-to-face mode. The thermodynamic parameters were estimated to be $\Delta H=-9.43 \mathrm{~kJ} \mathrm{~mol}^{-1}$ and $\Delta S=-28.3 \mathrm{~J} \mathrm{~mol}^{-1}$ by the van't Hoff plot (Table 2 and Supporting Information File 1). The self-association behavior is significantly affected by the solvent. While no association was observed in benzene- $d_{6}$ solution in the concentration ranges of $0.7-21 \mathrm{mM}$ even at low temperatures, a larger $K_{2}$ value was estimated in $\mathrm{CDCl}_{3}-\mathrm{CD}_{3} \mathrm{CN}$ solution $(3: 7 \mathrm{v} / \mathrm{v}$,<smiles>C#Cc1cc(C#C)cc(C#C)c1</smiles><smiles>Ic1cc(I)cc(I)c1</smiles><smiles>CCCCC</smiles><smiles>[AsH3]</smiles><smiles>[3H]C([3H])=C([3H])[3H]</smiles><smiles>C1CSCS1</smiles>

\section{0}

$\mathrm{Pd}\left(\mathrm{PPh}_{3}\right)_{4}, \mathrm{Cul}, \mathrm{Et}_{3} \mathrm{~N}$

$(75 \%)$

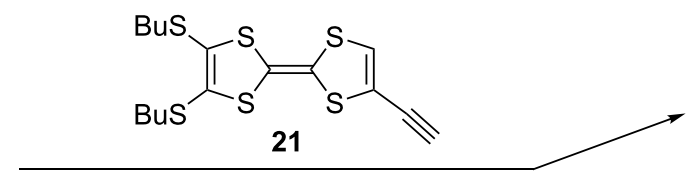

$\mathrm{Pd}\left(\mathrm{PPh}_{3}\right)_{4}, \mathrm{Cul}, \mathrm{Et}_{3} \mathrm{~N}$
$92 \%)$<smiles>[R5]C1=C([R5])SC(=C2SC=C(C#Cc3cc(C#CC4=CSC(=C(C)S)S4)cc(C#CC4=CSC(=C5SC([R5])=C([R5])S5)S4)c3)S2)S1</smiles>

22: $\mathrm{R}=\mathrm{Me}$

23: $\mathrm{R}=\mathrm{Bu}$ 


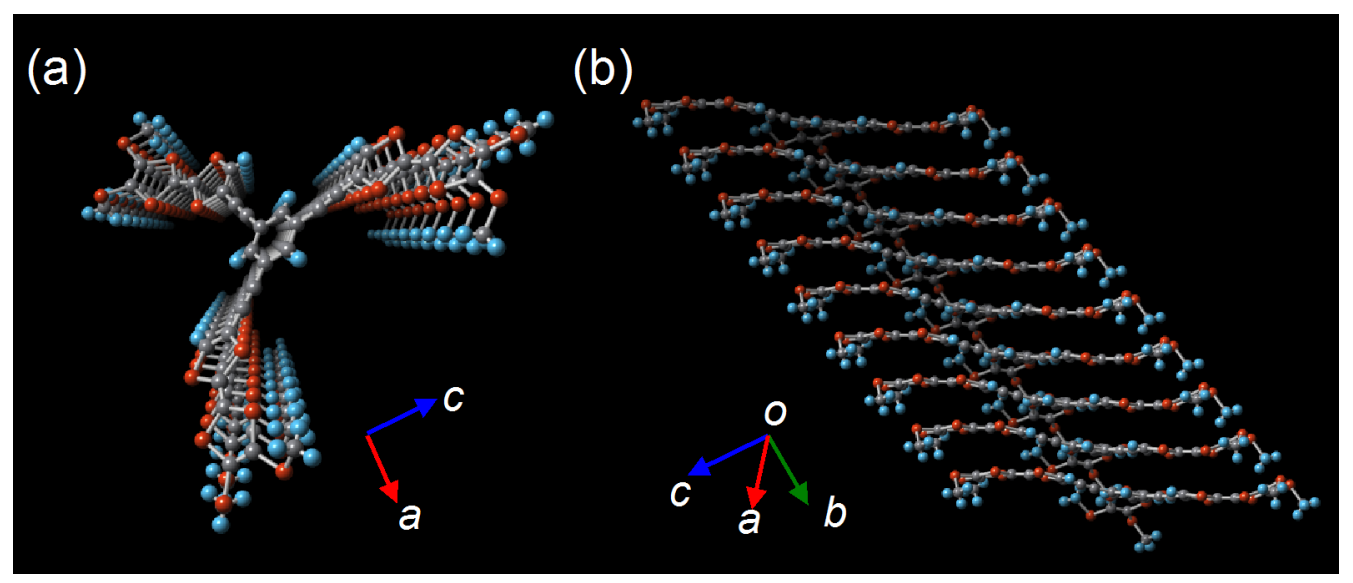

Figure 7: Projections of the molecular array of 22 in crystal structure (a) along with the $c$ axis and (b) from side view.

Table 2: Association (dimerization) constants and thermodynamic parameters of $\mathbf{2 3}$ in various solvents ${ }^{\mathrm{a}}$

\begin{tabular}{lllll} 
Solvent & $K_{2}\left(\mathrm{M}^{-1}\right)^{\mathrm{b}}$ & $\Delta G\left(\mathrm{~kJ} \mathrm{~mol}^{-1}\right)^{\mathrm{b}}$ & $\Delta H\left(\mathrm{~kJ} \mathrm{~mol}^{-1}\right)$ & $\left.\Delta S(\mathrm{~J} \mathrm{~mol})^{-1}\right)$ \\
\hline $\mathrm{CDCl}_{3}$ & 1.58 & -1.13 & -9.41 & -28.2 \\
$\mathrm{CDCl}_{3}-\mathrm{CD}_{3} \mathrm{CN}(3: 7)$ & 5.01 & -3.64 & -16.6 & -43.1 \\
benzene- $d_{6}$ & $-{ }^{\mathrm{c}}$ & $-{ }^{\mathrm{c}}$ & $-{ }^{\mathrm{c}}$ & $-{ }^{\mathrm{C}}$ \\
\hline
\end{tabular}

aParameters were estimated from titration experiments using ${ }^{1} \mathrm{H}$ NMR with the assumption of the dimerization process of $23 .{ }^{b} \mathrm{At} 298 \mathrm{~K}$. ${ }^{\mathrm{C}} \mathrm{No}$ association was observed.

$K_{2}=5.01 \pm 0.98 \mathrm{M}^{-1}$ at $293 \mathrm{~K}$ ). Moreover, only a small concentration dependence of the chemical shift, which could not be used for determination of the $K_{2}$ value, was observed in acetone- $\mathrm{CS}_{2}$ solution owing to very weak self-association. These results clearly suggest that the association behavior is driven by intermolecular $\pi-\pi, S \cdots S$, and/or $S \cdots H$ interactions in solution. Note that these $K_{2}$ values of $\mathbf{2 3}$ in the neutral state are similar to that of the mixed valence dimer $\left(\mathrm{TTF}^{\bullet+}+\mathrm{TTF}\right)$ $\left(K_{2}=6.0 \mathrm{M}^{-1}\right)$ and much larger than that of the $\pi$-dimer $\left(\mathrm{TTF}^{\bullet+}+\mathrm{TTF}^{\bullet+}\right)\left(K_{2}=0.6 \mathrm{M}^{-1}\right)$ described in the literature [61].

Strong self-association of $\mathbf{2 3}$ was observed in the oxidation state. $\mathrm{CV}$ analysis of $\mathbf{2 3}$ in a dilute $\mathrm{CH}_{2} \mathrm{Cl}_{2}$ solution $\left(1.9 \times 10^{-5} \mathrm{M}\right)$ showed two three-electron redox waves at 0.05 and $0.40 \mathrm{~V}$ vs Fc/ $/ \mathrm{Fc}^{+}$corresponding to the formation of $\mathbf{2 3}^{3+}$ and $\mathbf{2 3}^{6+}$, whereas a similar $\mathrm{CV}$ analysis of $\mathbf{2 3}$ in a concentrated $\mathrm{CH}_{2} \mathrm{Cl}_{2}$ solution $\left(1.2 \times 10^{-3} \mathrm{M}\right)$ displayed three reversible waves at $-0.04,0.14$, and $0.47 \mathrm{~V}$ vs $\mathrm{Fc} / \mathrm{Fc}^{+}$corresponding to the formation of $(\mathbf{2 3})_{2}{ }^{3+},(\mathbf{2 3})_{2}{ }^{6+}$, and $(\mathbf{2 3})_{2}{ }^{12+}$ (Figure S2, Supporting Information File 1). Interestingly, the three cationic species $\mathbf{2 3}^{\mathbf{}}, \mathbf{2 3}^{2+}$ and $\mathbf{2 3}^{3+}$ prepared by chemical oxidation with $\mathrm{Fe}\left(\mathrm{ClO}_{4}\right)_{3}$ in $\mathrm{CH}_{2} \mathrm{Cl}_{2} / \mathrm{CH}_{3} \mathrm{CN}$ (4:1) showed a strong selfassociation, and electronic spectra of $\mathbf{2 3}^{\circ+}$ and $\mathbf{2 3}^{2+}$ exhibited marked intermolecular charge resonance (CR) bands at $\lambda_{\max }$ 2000 (br, $\varepsilon$ 1500) and 2000 (br, $\varepsilon$ 1700) owing to the face-toface mixed valence interaction (Figure 8), and $\mathbf{2 3}^{3+}$ exhibited a typical Davydov blue shift ( $\left.\lambda_{\max } 738 \mathrm{~nm}, \varepsilon 27000\right)$ as compared with $19\left(\lambda_{\max } 796 \mathrm{~nm}\right.$, Table 1) [25]. To determine the

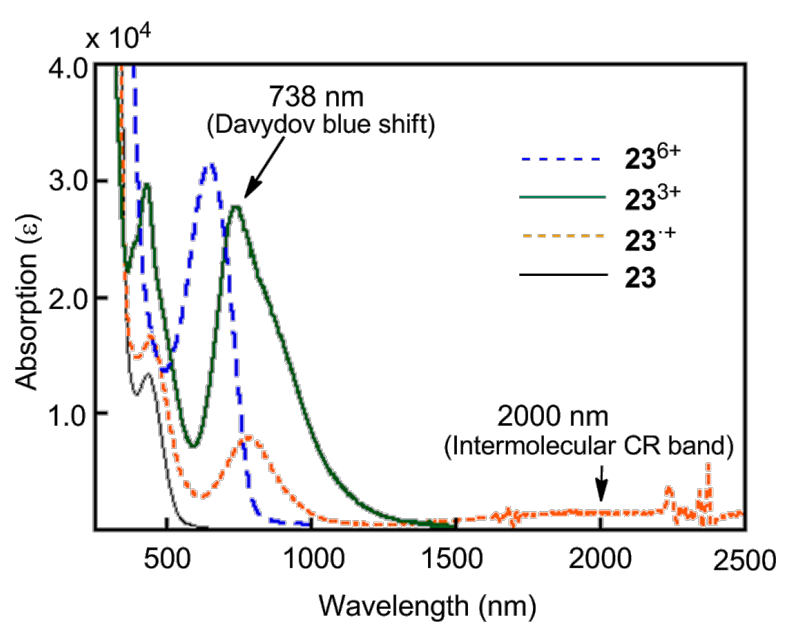

Figure 8: UV-vis/NIR spectra of $23,23^{{ }^{+}}, \mathbf{2 3}^{3+}$, and $23^{6+}$. 
conducting behavior of $\mathbf{2 2}$ and $\mathbf{2 3}$, a pellet of $\mathbf{2 2}$ was treated with iodine to produce a semiconducting black solid $\left(\sigma_{\mathrm{rt}}=3.6 \times 10^{-4} \mathrm{~S} \mathrm{~cm}^{-1}\right)$, whereas a similar doping of $\mathbf{2 3}$ with iodine resulted in the formation of the conducting liquid.

Radially expanded TTF oligomers with a large central $\pi$-surface can be expected to show effective intra- and intermolecular delocalization of electrons in the neutral and mixed-valence states. Furthermore, the supramolecular self-assembly of these large molecules having nanophase separation is a promising way of realizing molecular switches and devices [62-65]. With this in mind, hexadehydrotris(TTF)[12]annulenes $\mathbf{2 8}$ and $\mathbf{2 9}$ and dodecadehydrotris(TTF)[18]annulenes $\mathbf{3 0}$ and $\mathbf{3 1}$ were synthesized using palladium-mediated coupling reactions (Scheme 2) [20,25,26,66-68]. Tris(TTF)[12]annulenes $\mathbf{2 8}$ and $\mathbf{2 9}$ were pepared by Sonogashira coupling of $\mathbf{2 6}$ with $\mathbf{2 4}$ and $\mathbf{2 7}$ with $\mathbf{2 5}$ in 25 and $36 \%$ yields, respectively. For the synthesis of $\mathbf{3 0}$ and 31, cyclotrimerization of $\mathbf{2 4}$ and $\mathbf{2 5}$ with a stoichiometric amount of $\mathrm{PdCl}_{2}\left(\mathrm{PPh}_{3}\right)_{2}$ and $\mathrm{CuI}$ in triethylamine-THF was employed to afford $\mathbf{3 0}$ and $\mathbf{3 1}$ in 32 and 29\% yields, respectively. Although tris(TTF)[18]annulenes are stable at room temperature in air, tris(TTF)[12]annulenes $\mathbf{2 8}$ and $\mathbf{2 9}$ gradually decomposed under ambient conditions due to the instability of central $4 n \pi$-electron system.

In order to investigate the effect of fused two TTF units on the cyclic conjugation and the interaction of the two TTF units in the neutral and cationic states, TTF-fused annulenes 33 [69] and radiannulenes 34 and 35 [70] were synthesized using a Sonogashira coupling in moderate yields (Figure 9).

The thermodynamic study on the self-aggregation of tris(TTF)annulenes indicates that the aggregation of $\mathbf{2 8 , 3 0}$, and 31 is an enthalpically driven process that is entropically disfavored (Table 3) [68], although the aggregation of planar macrocyclic belts is both enthalpically and entropically driven [71]. The TTF[18]annulene $\mathbf{3 0}$ has smaller $\Delta H$ and $\Delta S$ values than the TTF[12]annulene 28, suggesting a higher stacking ability and a larger ring size for 30. Alkyl-substituted TTF[18]annulene 32 was reported to show almost no aggregation behavior in solution [72]. However, the slightly more amphiphilic 31 exhibits self-aggregation in benzene, toluene, and cyclohexane owing to a slightly larger nanophase separation in $\mathbf{3 1}$. It is worth noting that the self-aggregation of TTF-annulenes results in the<smiles>[R]C1=C([R])SC(=C2SC(C#C)=C(C#C)S2)S1</smiles>

24: $\mathrm{R}=\mathrm{CO}_{2} \mathrm{C}_{4} \mathrm{H}_{9}$ 25: $\mathrm{R}=\mathrm{SC}_{4} \mathrm{H}_{9}$<smiles>[R]C1=C([R])SC(=C2SC(C#C)=C(C#C)S2)S1</smiles>

24: $\mathrm{R}=\mathrm{CO}_{2} \mathrm{C}_{4} \mathrm{H}_{9}$ 25: $\mathrm{R}=\mathrm{SC}_{4} \mathrm{H}_{9}$
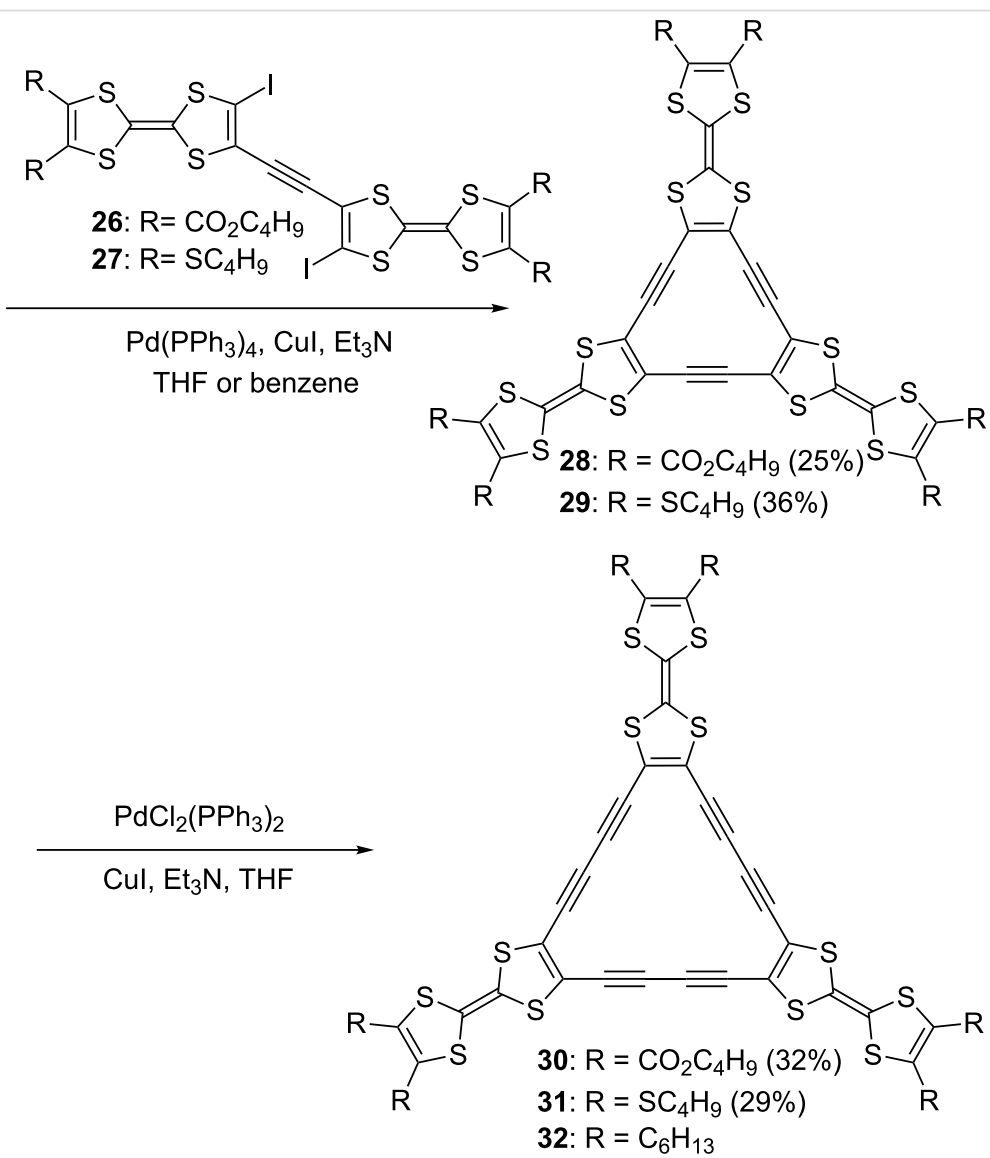

Scheme 2: Synthesis of tris(TTF)[12]annulenes 28 and 29 and tris(TTF)[18]annulenes 30 and 31, together with hexyl-substituted tris(TTF)[18]annulene 32. 


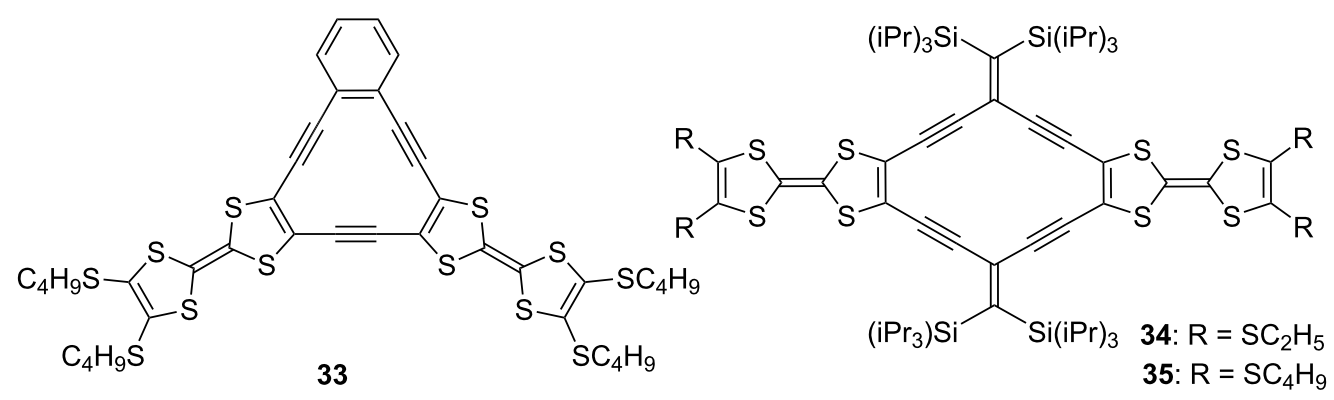

Figure 9: TTF-fused annulene 33 and radiannulenes 34 and 35.
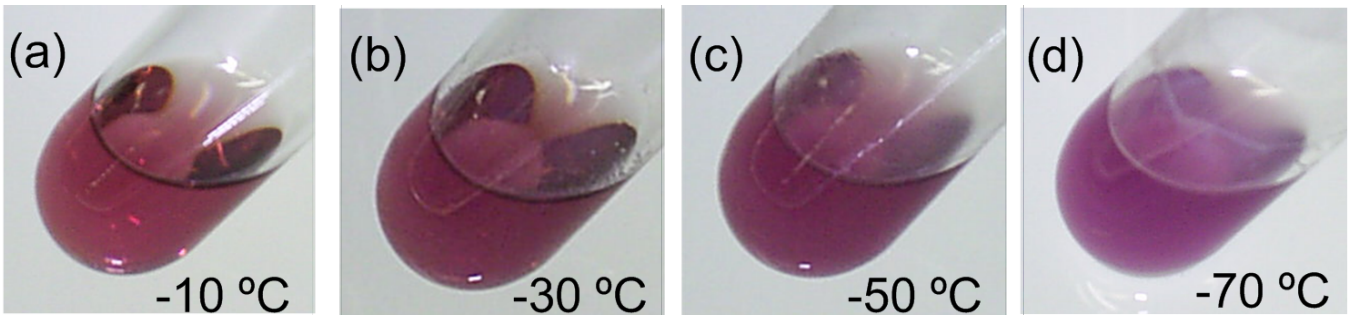

Figure 10: Colors of 30 solutions a-d in toluene $(0.025 \mathrm{mM})$ at various temperatures. (a) $\lambda_{\max }: 511 \mathrm{~nm}$, (b) $\lambda_{\max }: 512 \mathrm{~nm}$, (c) $\lambda_{\max }: 517 \mathrm{~nm}$, (d) $\lambda_{\text {max }}: 520 \mathrm{~nm}$. Reprinted with permission from [68]. Copyright 2012 Chemical Society of Japan.

\begin{tabular}{|c|c|c|c|}
\hline Comp. & $\begin{array}{l}\Delta G\left(\mathrm{~kJ} \mathrm{~mol}^{-1}\right) \\
\text { at } 303 \mathrm{~K}\end{array}$ & $\Delta H\left(\mathrm{~kJ} \mathrm{~mol}^{-1}\right)$ & $\Delta S\left(\mathrm{~J} \mathrm{~mol}^{-1} \cdot \mathrm{K}^{-1}\right)$ \\
\hline 28 & -11.8 & -32.0 & -66.3 \\
\hline 30 & -14.5 & -37.8 & -77.0 \\
\hline 31 & -10.1 & -21.5 & -37.1 \\
\hline
\end{tabular}

a Determined with concentration/temperature-dependent ${ }^{1} \mathrm{H}$ NMR assuming an infinite association model [68].

appearance of solvatochromism and thermochromism [68]. As shown in Figure 10, 30 exhibits a supramolecular thermochromism in toluene, and the color at $-10{ }^{\circ} \mathrm{C}$ is reddish purple, whereas the color at $-70{ }^{\circ} \mathrm{C}$ is purple. On the other hand, as shown in Figure 11, a solution of $\mathbf{3 3}$ exhibits deep green in $\mathrm{CS}_{2}$ but purple in $\mathrm{CH}_{2} \mathrm{Cl}_{2}$ [69].

$\mathrm{CV}$ analysis of $\mathbf{2 8 - 3 4}$ in solution showed different behaviors (Table 4). The [12]annulenes $\mathbf{2 8}, \mathbf{2 9}$, and $\mathbf{3 3}$ exhibited two reversible one-electron reductions due to the smooth reduction of the $12 \pi$ electron system to a $14 \pi$ electron system, whereas the [18]annulenes $\mathbf{3 0}$ and $\mathbf{3 1}$ showed an irreversible reduction wave, due to the unfavorable reduction of the aromatic $18 \pi$ electron system. On the other hand, all the molecules exhibited reversible oxidation waves in $\mathrm{CH}_{2} \mathrm{Cl}_{2}$ based on the high HOMO (a)

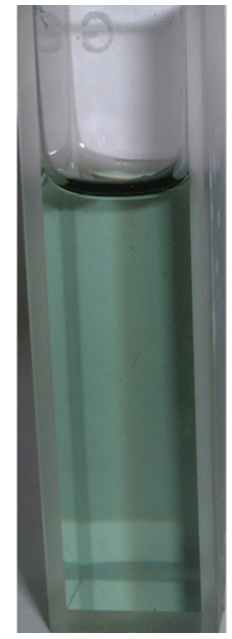

(b)

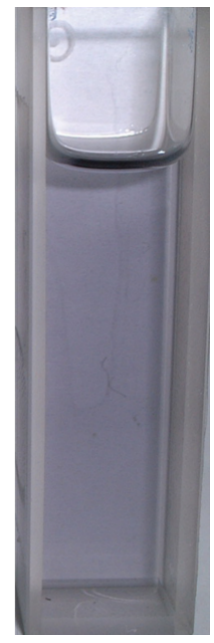

Figure 11: Solutions of 33. (a) In $\mathrm{CS}_{2}, \lambda_{\max }: 608 \mathrm{~nm}$. (b) In $\mathrm{CH}_{2} \mathrm{Cl}_{2}$, $\lambda_{\max }: 577 \mathrm{~nm}$. Reprinted with permission from [69]. Copyright 2004 Royal Society of Chemistry.

levels of TTF units. Another important feature in the CV data of 28-32 is broadening or splitting of the first oxidation wave, indicating intra- and/or intermolecular interactions between TTF units [68]. Interestingly, the first oxidation potential of $\mathbf{2 8}$ and 29 splited at the slow scanning rate of $3 \mathrm{mV} \mathrm{s}^{-1}$ owing to the intermolecular mixed-valence interaction between the $\mathrm{TTF}^{\bullet+}$ 


\begin{tabular}{|c|c|c|c|c|}
\hline Compound & $E_{1 / 2}^{\text {red2 }}(\mathrm{V})$ & $E_{1 / 2}^{\text {red1 }}(\mathrm{V})$ & $E_{1 / 2}{ }^{\mathrm{ox} 1}(\mathrm{~V})$ & $E_{1 / 2}{ }^{o \times 2}(\mathrm{~V})$ \\
\hline $28^{b}$ & $-1.52(1 e)$ & $-1.16(1 \mathrm{e})$ & $0.38(3 e)[0.29,0.44]^{c}$ & $0.66(3 e)$ \\
\hline $29^{b}$ & $-1.78(1 e)$ & $-1.41(1 e)$ & $0.21(3 e)[0.12,0.26]^{c}$ & $0.49(3 e)$ \\
\hline $30^{b}$ & $-^{d}$ & $-1.35^{\mathrm{e}}$ & $0.43(3 e)^{f}$ & $0.70(3 e)$ \\
\hline $31^{b}$ & $-d$ & $-1.48^{e}$ & $0.14(1 \mathrm{e}), 0.29(2 \mathrm{e})$ & $0.53(3 e)$ \\
\hline $32^{\mathrm{g}}$ & $-d$ & $-1.40^{\mathrm{e}}$ & $0.20(3 e)$ & $0.64(3 e)$ \\
\hline $33^{b, i}$ & $-1.87(1 \mathrm{e})$ & $-1.50(1 \mathrm{e})$ & $0.19(2 e)^{f, h}$ & $0.46(2 e)^{h}$ \\
\hline $34^{i}$ & $-1.52(1 \mathrm{e})$ & $-1.16(1 \mathrm{e})$ & $0.20(1 \mathrm{e}), 0.29(1 \mathrm{e})$ & $0.61(2 e)$ \\
\hline
\end{tabular}

aConditions: $0.1 \mathrm{M} \mathrm{Bu}_{4} \mathrm{NClO}_{4}, 100 \mathrm{mV} \mathrm{s}^{-1}$, Pt as a working electrode, $\mathrm{Ag} / \mathrm{Ag}^{+}$as a reference electrode, Pt wire as a counter electrode. Potentials were referenced to $\mathrm{Fc} / \mathrm{Fc}^{+}$. Solvent: THF for reduction, and $\mathrm{CH}_{2} \mathrm{Cl}_{2}$ for oxidation. ${ }^{\mathrm{b}}$ Concentration: $0.1 \mathrm{mM}$. ${ }^{\mathrm{C}} \mathrm{Measured}$ at $3 \mathrm{mV} \mathrm{s}{ }^{-1}$. ${ }^{\mathrm{d}} \mathrm{Not}$ observed. eIrreversible process. fBroad redox wave. gAccording to [72]. hSolvent: benzonitrile. 'According to [70].

and TTF moieties under diffusion-controlled conditions. In the case of 31, the first oxidation potential $\left(E_{1 / 2}=0.14 \mathrm{~V}\right.$ vs $\left.\mathrm{Fc} / \mathrm{Fc}^{+}\right)$is lower than that of $\mathbf{3 2}$ with alkyl groups $\left(E_{1 / 2}=0.20 \mathrm{~V}\right)$. Since the first oxidation potential of $\mathbf{3 1}$ in a dilute solution broadened but did not split $\left(E_{1 / 2}{ }^{\text {ox } 1}\right.$ in $\mathrm{CH}_{2} \mathrm{Cl}_{2}$ : $0.23(3 \mathrm{e}) \mathrm{V}$ ), the potential of $\mathbf{3 1}$ at $0.14 \mathrm{~V}$ (Table 4) reflected the strong intermolecular interaction between the $\mathrm{TTF}^{\bullet+}$ and TTF moieties in $\mathbf{3 1}^{\boldsymbol{}^{+}}$. By comparison with the known UV-vis/NIR spectra of mixed valence dimers [18,73], the association constant $K_{\mathrm{a}}$ of $\mathbf{3 1}{ }^{\bullet+}$ measured in $\mathrm{CH}_{2} \mathrm{Cl}_{2}-\mathrm{MeCN}$ 4:1 assuming an infinite association model [74] is large $\left(K_{\mathrm{a}}=3.12 \pm 0.48 \times 10^{5} \mathrm{M}^{-1}\right.$ at $\left.298 \mathrm{~K}\right)$ owing to 18 sulfur atoms in 31. Therefore, the oxidation of $\mathbf{3 1}$ solution $(0.1 \mathrm{mM})$ in $\mathrm{CH}_{2} \mathrm{Cl}_{2}$ first forms (31) ${ }_{2}{ }^{2+}$ owing to the intermolecular mixvalence interaction between the $\mathrm{TTF}^{\circ+}$ and TTF moieties, and the further oxidation forms $\mathbf{3 1}^{3+}$ [68]. In summary, the oxidation of 28-31 showed multistep processes owing to intraand/or intermolecular interactions between TTF units. In the case of [18]annulene 31, the first oxidation potential splited in two with the strong intermolecular interaction in $\mathbf{3 1}^{\circ}$. TTFfunctionalized radiaannulenes (RAs) $\mathbf{3 4}$ and $\mathbf{3 5}$ also exhibit multiple redox states [70]. CV analysis of $\mathbf{3 4}$ shows the two reversible one-electron reductions as the reduction of the RA core, whereas the three reversible oxidations at $0.20,0.29$, and $0.61 \mathrm{~V}$ correspond to the formation of $\mathbf{3 4}^{\mathbf{}}, \mathbf{3 4}^{2+}$, and $34^{4+}$. Therefore, the redox behavior of $\mathbf{3 4}$ is similar to those of $\mathbf{2 8 , 2 9}$, and 31.

The [18]annulenes $\mathbf{3 0}$ and $\mathbf{3 1}$ formed a fibrous structure in $\mathrm{H}_{2} \mathrm{O}-\mathrm{THF}$ 1:1, and $\mathbf{3 1}$ required longer time for fiber formation than 30 owing to weaker association constant in solution $\left(K_{\mathrm{a}}\right.$ in toluene- $d_{8}$ at $\left.303 \mathrm{~K}=634 \mathrm{M}^{-1}(\mathbf{3 0}), 101 \mathrm{M}^{-1}(\mathbf{3 1})\right)[67,68]$. Both $\mathbf{3 0}$ and $\mathbf{3 1}$ fibers showed roughly the same behavior for doping with iodine, and the color of fibers quickly changed from bluish purple to dark brown due to the partial oxidation of $\mathbf{3 0}$ and $\mathbf{3 1}$ as shown Figure 12 (the maximum conductivities: 30 $\sigma_{\mathrm{rt}} 2.0 \times 10^{-2} \mathrm{~S} \mathrm{~cm}^{-1}, \mathbf{3 1} \sigma_{\mathrm{rt}} 2.6 \times 10^{-3} \mathrm{~S} \mathrm{~cm}^{-1}$ ). The color of the doped fibers gradually returned to the original bluish purple under vacuum, but the speed of the iodine desorption for fiber 31 was very slow. The conductivity of the doped pellet prepared from fiber $\mathbf{3 0}$ is estimated to be ca. 1000 times higher than that of the neutral fiber (before doping: $\sigma_{\mathrm{rt}} 3 \times 10^{-6} \mathrm{~S} \mathrm{~cm}^{-1}$, after doping: $\sigma_{\mathrm{rt}} 3 \times 10^{-3} \mathrm{~S} \mathrm{~cm}^{-1}$ ) [68].

Star-shaped pyrrole-fused TTF oligomers 38-43 were synthesized by nucleophilic aromatic substitution $\left(\mathrm{S}_{\mathrm{N}} \mathrm{Ar}\right)$ reactions of fluorinated benzenes with the pyrrolyl sodium salts derived from 36 and 37 in moderate yields (Scheme 3) [23]. X-ray analysis of $\mathbf{3 8}$ revealed that the three TTF units are bent simply to fill an empty space and stacked to form a columnar structure. The torsion angle between the mean planes of the pyrrole and central benzene is $7-32^{\circ}$, indicating the conformational flexibility of the pyrrole-benzene linkage. The calculated torsion angles between the pyrroles and central benzenes of $\mathbf{3 8}, \mathbf{4 0}$, and 42 are 34,45 , and $59^{\circ}$, respectively, and the non-planar structures of 38, 40, and $\mathbf{4 2}$ are in good agreement with the highfield shift of $\alpha$-protons of pyrroles in the ${ }^{1} \mathrm{H}$ NMR spectra: $\delta 6.89$ (38), 6.41 (40), 5.93 ppm (42). Star-shaped TTF 10-mer 44 was also synthesized by $S_{N} A r$ reaction of the sodium salt of 36 with decafluorobiphenyl (44\%) [75] (Figure 13).

In the CV measurements (Figure 14), tetrasubstituted $\mathbf{4 0}$ shows typical two reversible oxidation waves at $E_{1 / 2}{ }^{\text {ox } 1}=0.044$ and $E_{1 / 2}{ }^{\text {ox } 2}=0.35 \mathrm{~V}\left(\mathrm{vs} \mathrm{Fc} / \mathrm{Fc}^{+}\right)$. However, trisubstituted 38 and hexasubstituted $\mathbf{4 2}$ exhibit split and broad first peaks, respectively, at -0.086 and $0.020 \mathrm{~V} \mathrm{(38)}$ and $0.097 \mathrm{~V} \mathrm{(42)}$, followed by second peaks at $0.45 \mathrm{~V}(\mathbf{3 8})$ and $0.37 \mathrm{~V}(\mathbf{4 2})$. The CV data of tetrasubstituted $\mathbf{4 0}$ suggests no intramolecular charge delocalization between the adjacent TTF units. The splitting and broadening of the first oxidation waves in $\mathbf{3 8}$ and $\mathbf{4 2}$ are considered to be caused by intermolecular interactions between the neutral and cationic TTF units. 
(a)

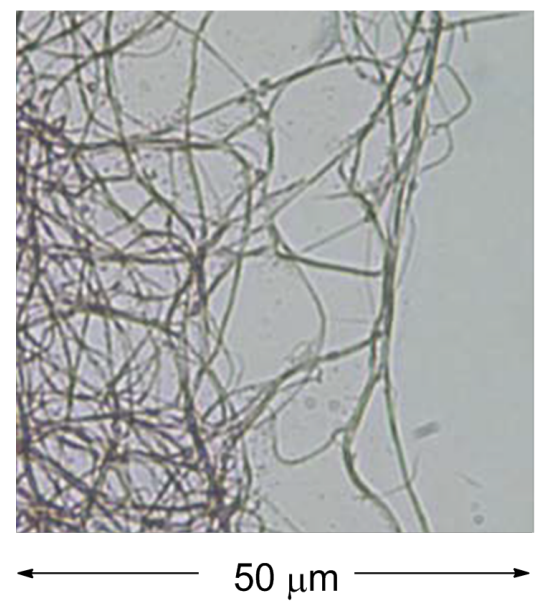

(b)

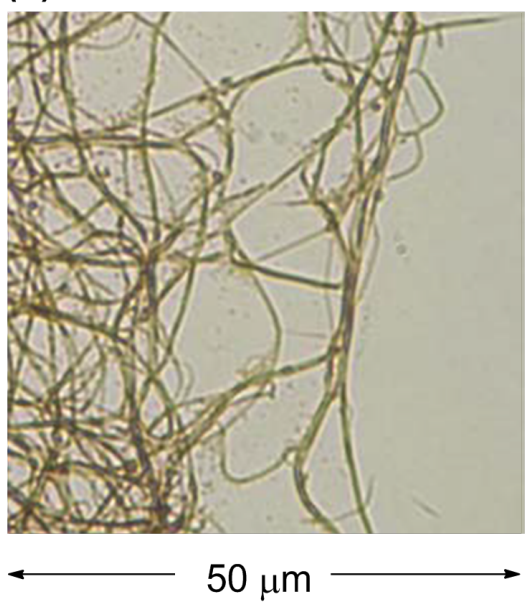

Figure 12: Optical micrographs (1000 $\times$ magnified) of fibers, prepared from 30 in THF- $\mathrm{H}_{2} \mathrm{O} 1: 1$, on a glass plate at $23^{\circ} \mathrm{C}$. (a) Before iodine doping. (b) After iodine doping (3 min). Reprinted with permission from [26]. Copyright 2010 Royal Society of Chemistry.

As shown in Figure 15, the stepwise chemical oxidation of $\mathbf{3 8}$, 40, and 42 with $\mathrm{Fe}\left(\mathrm{ClO}_{4}\right)_{3}$ in $\mathrm{CH}_{2} \mathrm{Cl}_{2}-\mathrm{CH}_{3} \mathrm{CN}$ 2:1 exhibits the typical changes in the absorption spectra. The addition of $\mathrm{Fe}\left(\mathrm{ClO}_{4}\right)_{3}$ up to 1 equiv with respect to each of the TTF units causes new absorption maxima at longer wavelength region (blue to green spectra). For the oxidation of 40, the changes show several isosbestic points, indicating that each TTF unit is oxidized from the neutral to the radical cation $\left(\mathrm{TTF}^{\circ+}\right)$ in a stepwise manner (Figure 15b). On the other hand, for $\mathbf{3 8}$ and $\mathbf{4 2}$, there are no isosbestic points (Figure 15a,c). For 38, a new broad peak around $1850 \mathrm{~nm}$ (intermolecular CR absorption) appears in the presence of 1.5 equiv of $\mathrm{Fe}\left(\mathrm{ClO}_{4}\right)_{3}$, which is attributed to the formation of an intermolecular face-to-face mixed valence complex. These results are consistent with the peak splitting of the CV. Furthermore, CV analysis of $\mathbf{4 4}$ exhibited two reversible ten-electron redox waves corresponding to the formation of $\mathbf{4 4 ^ { 1 0 + }}$ and $\mathbf{4 4 ^ { 2 0 + }}$.

Trisubstituted $\mathbf{3 8}$ showed polymorphism and formed single crystals from $\mathrm{CH}_{2} \mathrm{Cl}_{2}$, whereas it produced a yellow fibrous material from $\mathrm{CH}_{2} \mathrm{Cl}_{2}$-hexane 1:4. X-ray diffractometry (XRD) exhibited that fiber $\mathbf{3 8}$ possesses a hexagonal columnar structure different from single crystals. Furthermore, the spin-coated film of $\mathbf{3 8}$ has an amorphous structure. Interestingly, doping of single crystals, hexagonal fiber, and amorphous film of $\mathbf{3 8}$ with iodine vapor produced black CT-complexes having different assembled structure. After doping, electric conductivity of single crystals was $\sigma_{\mathrm{rt}}=1.8 \times 10^{-2} \mathrm{~S} \mathrm{~cm}^{-1}$ and the fiber was $1.9 \times 10^{-2} \mathrm{~S} \mathrm{~cm}^{-1}$, whereas the amorphous film was $2.5 \times 10^{-3} \mathrm{~S} \mathrm{~cm}^{-1}$. The difference in the conductivity reflects the molecular level alignments. Other star-shaped oligomers 39-44 also formed nanostructures fibers, particles and film, and doping with iodine produced black complexes which exhibited electric conductivities of $\sigma_{\mathrm{rt}}=2.7 \times 10^{-3}-2.4 \times 10^{-2} \mathrm{~S} \mathrm{~cm}^{-1}$ in spite of the non-planarity of the molecular frame of 39-44.

The pyridazine-3,6-diol-annulated TTF derivative $\mathbf{4 5}$ produced trimer 46 via hydrogen bonds in a $\mathrm{THF}-\mathrm{H}_{2} \mathrm{O}$ solution (Scheme 4), in which micrometer-sized fibrous material was gradually formed [76]. The compressed pellet of the $\mathbf{4 6}$ fibers showed an electrical conductivity of $\sigma_{\mathrm{rt}}=2.3 \times 10^{-4} \mathrm{~S} \mathrm{~cm}^{-1}$ after doping with iodine vapor. The addition of ethylene diamine triggered the reorganization of the supramolecular structure 46, and fine nanoscopic fibers composed of 45 and ethylene diamine $(1: 1)$ were produced from the $\mathrm{CHCl}_{3}$ solution. A compressed pellet of the fibers of $45 \cdot \mathrm{H}_{2} \mathrm{NCH}_{2} \mathrm{CH}_{2} \mathrm{NH}_{2}$ exhibited an electrical conductivity in the range of $\sigma_{\mathrm{rt}}=1.5-10.0 \times 10^{-5} \mathrm{~S} \mathrm{~cm}^{-1}$ after iodine doping.

Recently, conducting nanofibers derived from the self-assembly of TTF-appended dipeptides were reported [77]. Conductivity measurements performed on the nanofibers of TTF-appended dipeptides indicate a remarkable enhancement in the conductivity after doping with TCNQ $\left(\sigma_{\mathrm{rt}}=1 \times 10^{-5} \mathrm{~S} \mathrm{~cm}^{-1}\right)$.

\section{Conducting nanostructures prepared from cation radicals}

Molecular conductors derived from CT complexes and radical salts of TTFs are widely known [1], and mixed-valence $\left(\mathrm{TTF}_{2}\right)^{n+}(0<n<1)$ was reported to form self-accembled conducting nanofibers $\left(\sigma_{\mathrm{rt}}=\sim 10^{-2} \mathrm{~S} \mathrm{~cm}^{-1}\right)$ [78-82]. However, there is only a limited number of examples of nanofibers and nanorods prepared from CT complexes and radical salts of starshaped and radially expanded TTF oligomers. One typical 

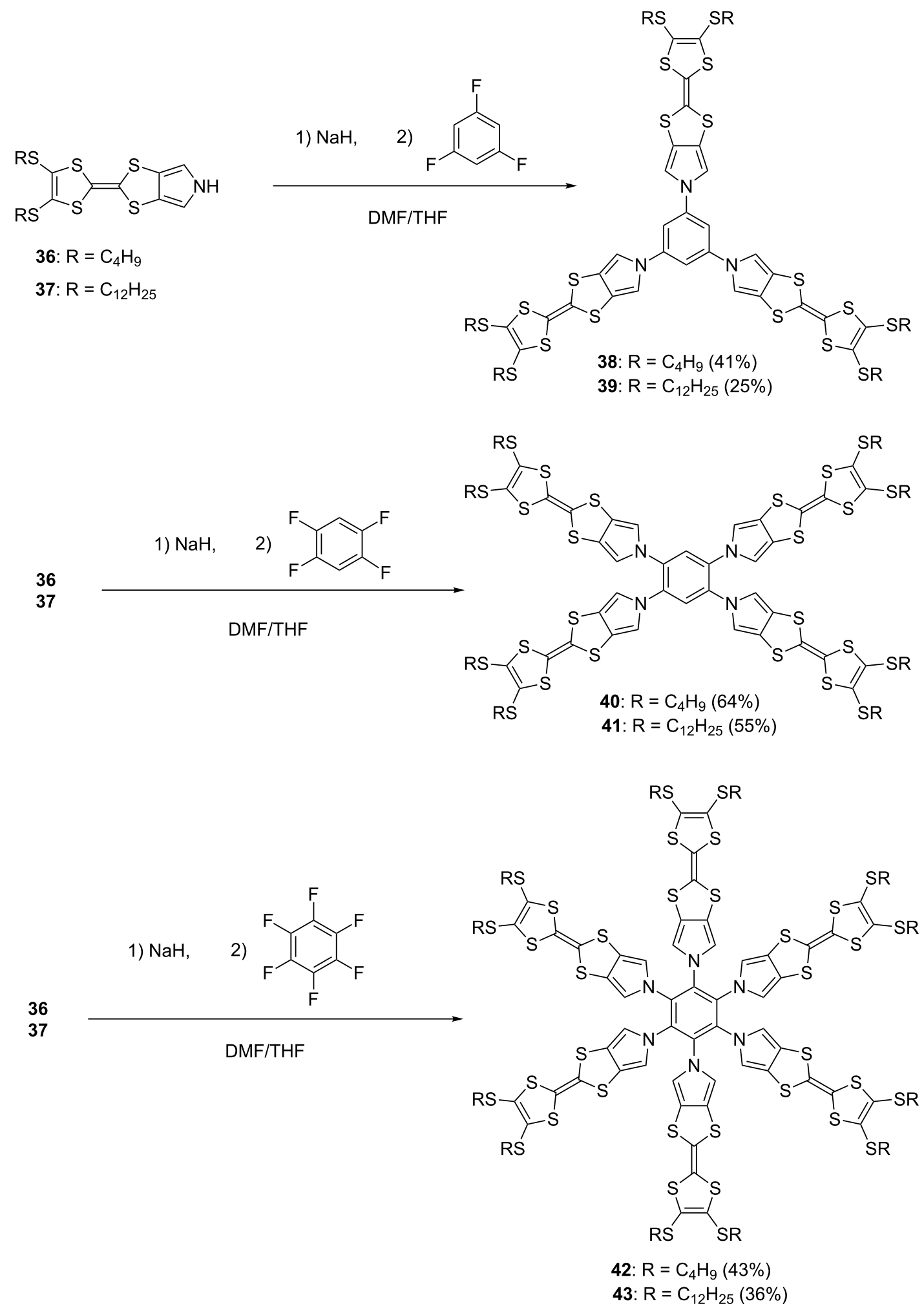


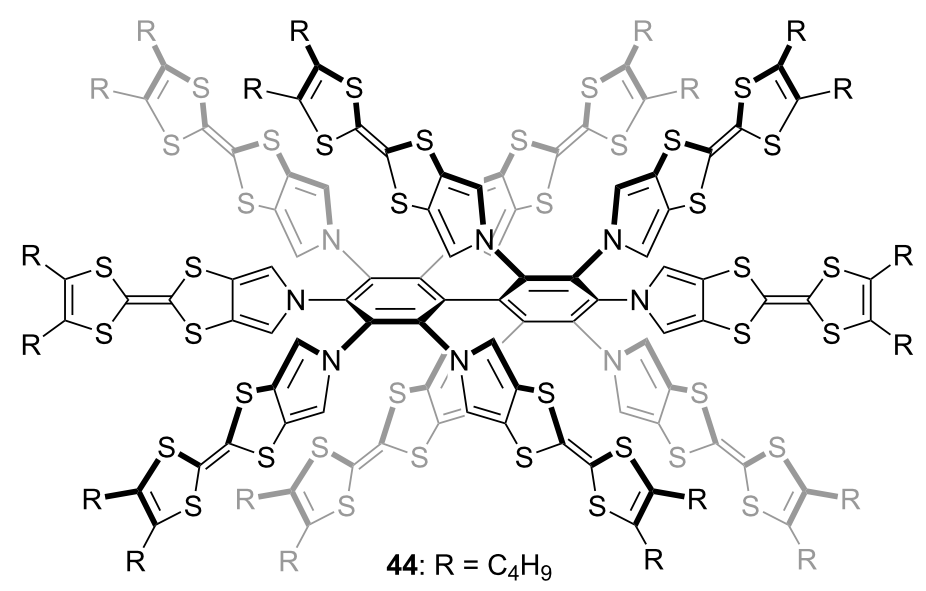

Figure 13: Star-shaped TTF 10-mer 44.

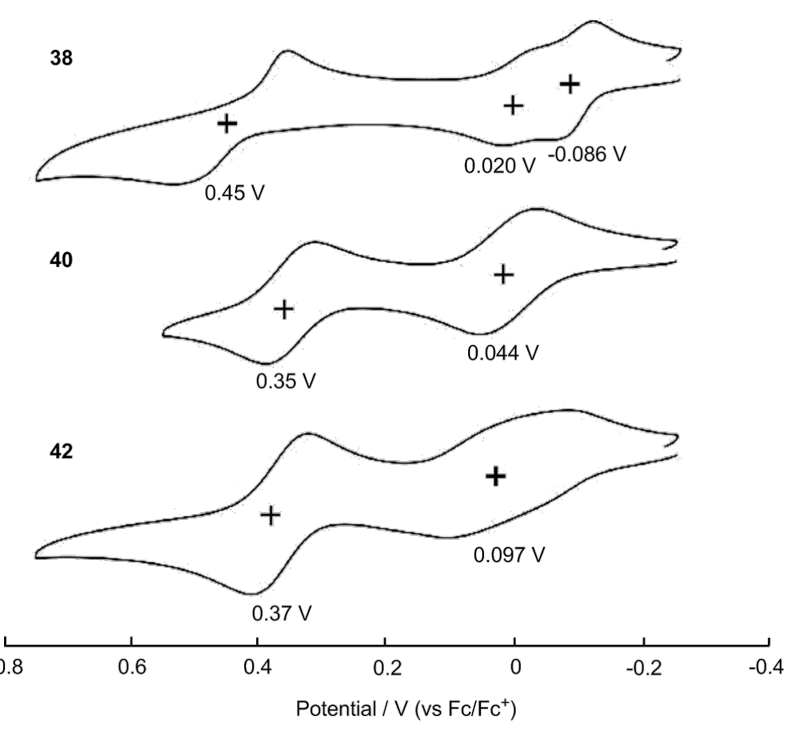

Figure 14: Cyclic voltammograms of 38,40 , and $42(0.1 \mathrm{mM})$ in benzonitrile with $0.1 \mathrm{M} \mathrm{n}-\mathrm{Bu}_{4} \mathrm{PF}_{6}$ as a supporting electrolyte, $\mathrm{Ag} / \mathrm{AgNO}_{3}$ as a reference electrode, glassy carbon as a working electrode, $\mathrm{Pt}$ wire as a counter electrode, and a scan rate of $100 \mathrm{mV} \mathrm{s}^{-1}$. Values are half-wave potentials. Adapted with permission from [23]. Copyright 2011 American Chemical Society.

example is the conducting CT complex $47^{2+} \cdot\left(\mathrm{TCNQF}_{4}{ }^{-{ }^{-}}\right)_{2}$ of amphiphilic TTF 47 and $\mathrm{TCNQF}_{4}$ (Figure 16) [83,84]. The fiber structure with typical dimensions of $2.5 \mathrm{~nm}$ (height) $\times$ $50 \mathrm{~nm}$ (width) $\times 1 \mu \mathrm{m}$ (length) was constructed on a mica substrate by using the Langmuir-Blodgett (LB) technique, and the conductivity of the film composed the $47^{2+}$. $\left(\mathrm{TCNQF} 4^{--}\right)_{2}$ fiber was found to be on the order of $\sigma_{\mathrm{rt}}=10^{-3} \mathrm{~S} \mathrm{~cm}^{-1}$.
The stacking behavior of TTF in solution and in the solid state was employed as a driving force to construct higher aggregates by using the star-shaped hexakis(tetrathiafulvalenylethynyl)benzene 48 (Figure 17a). The TTF-hexamer 48 was synthesized by Sonogashira coupling of $\mathbf{2 1}$ with hexaiodobenzene (52\%) [22]. As expected, 48 strongly self-aggregates in $\mathrm{CHCl}_{3}\left(K_{\mathrm{a}}=2.1 \times 10^{4} \mathrm{M}^{-1}, 23{ }^{\circ} \mathrm{C}\right)$ and in other common organic solvents. To construct nanoobjects, $\mathrm{CHCl}_{3}$ solution of 48 was diluted with hexane to afford dark blue fibers with a slim and curled fiber structure (40-90 nm wide, 30-100 nm thick and more than $10 \mu \mathrm{m}$ long) (Figure 17b). On the other hand, a dark blue film was formed by casting a solution of $\mathbf{4 8}$ on a glass surface (Figure 17c). XRD studies on the fiber and the film of $\mathbf{4 8}$ revealed that the fiber has a hexagonal alignment, whereas the film has a lamellar structure with lateral order and $\pi \cdots \pi$ stacking. It is worth noting that the film of $\mathbf{4 8}$ prepared by casting a $0.1 \mathrm{wt} \%$ solution of $\mathbf{4 8}$ in $\mathrm{CHCl}_{3}$ exhibited a low carrier mobility of $\mu=3 \times 10^{-6} \mathrm{~cm}^{2} \mathrm{~V}^{-1} \mathrm{~s}^{-1}$, indicating a lamellar structure vertical to the substrate surface.

Oxidation of 48 with 1 and 3 equiv of $\mathrm{Fe}\left(\mathrm{ClO}_{4}\right)_{3}$ produced the analytically pure monocation $\mathbf{4 8}^{\circ} \mathrm{ClO}_{4}{ }^{-}$and trication $\mathbf{4 8}^{3+}\left(\mathrm{ClO}_{4}{ }^{-}\right)_{3}$, respectively. The cationic species $\mathbf{4 8}^{\bullet+} \mathrm{ClO}_{4}{ }^{-}$ and $\mathbf{4 8}^{3+}\left(\mathrm{ClO}_{4}{ }^{-}\right)_{3}$ strongly self-aggregate in $\mathrm{CHCl}_{3}$ $\left(K_{\mathrm{a}}=2.3-2.5 \times 10^{6} \mathrm{M}^{-1}\right)$ and rather weakly aggregate in THF. Interestingly, in THF, $\mathbf{4 8}^{\cdot+} \mathrm{ClO}_{4}{ }^{-}$and $\mathbf{4 8}^{3+}\left(\mathrm{ClO}_{4}{ }^{-}\right)_{3}$ exhibited the formation of stacked cylindrical structures with a radius of $11 \AA$ and a height of $14-16 \AA$ by small-angle X-ray scattering (SAXS). ESR spectra of $\mathbf{4 8}^{\circ+}$ and $\mathbf{4 8}^{3+}$ in $\mathrm{CHCl}_{3}$ at $23{ }^{\circ} \mathrm{C}$ showed $100 \%$ of spin for $\mathbf{4 8}^{\cdot+}$ and $33 \%$ of spin for $\mathbf{4 8}^{3+}$. Therefore, the spin-spin interaction in $\mathbf{4 8}^{\mathbf{}}$ is weak, whereas the spin-spin interaction in $\mathbf{4 8}^{3+}$ is strong. 

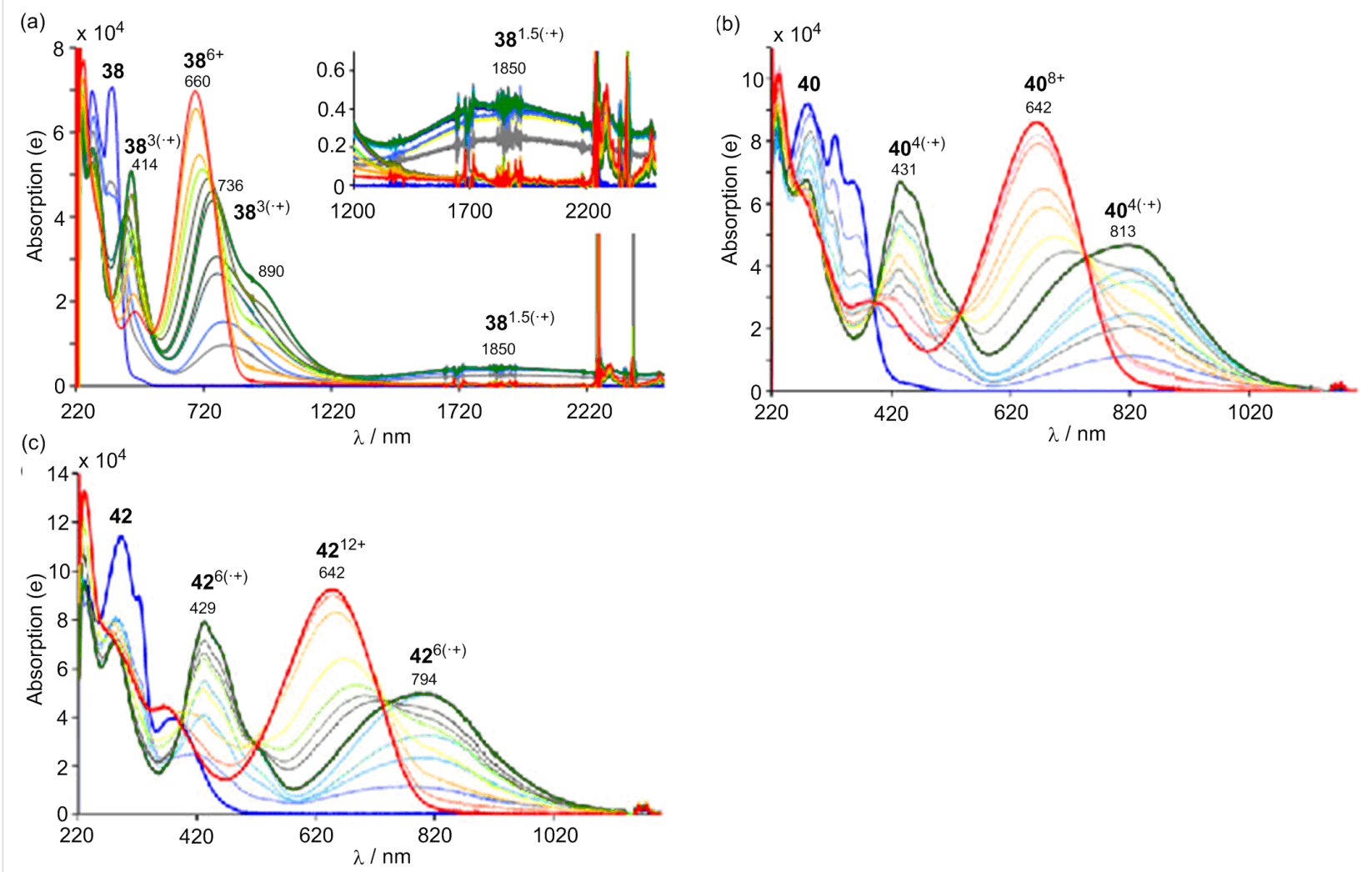

Figure 15: Stepwise oxidation of (a) $38(0.02 \mathrm{mM})$, (b) $40(0.05 \mathrm{mM})$, and (c) $42(0.03 \mathrm{mM})$ with incremental addition of $\mathrm{Fe}(\mathrm{ClO})_{3}$ in a mixture of $\mathrm{CH}_{2} \mathrm{Cl}_{2}-\mathrm{CH}_{3} \mathrm{CN}(2: 1, \mathrm{v} / \mathrm{v})$ at $25^{\circ} \mathrm{C}$. The blue line indicates the neutral absorption spectra, the green line the multiple TTF radical cations $38^{3(\cdot+)}$, $\mathbf{4 0} \mathbf{4}^{4(+)}$, and $\mathbf{4 2} \mathbf{2}^{6(+)}$, and the red line the TTF dications $38^{6+}, \mathbf{4 0}^{8+}$, and $\mathbf{4 2}{ }^{12+}$. Adapted with permission from [23]. Copyright 2011 American Chemical Society.

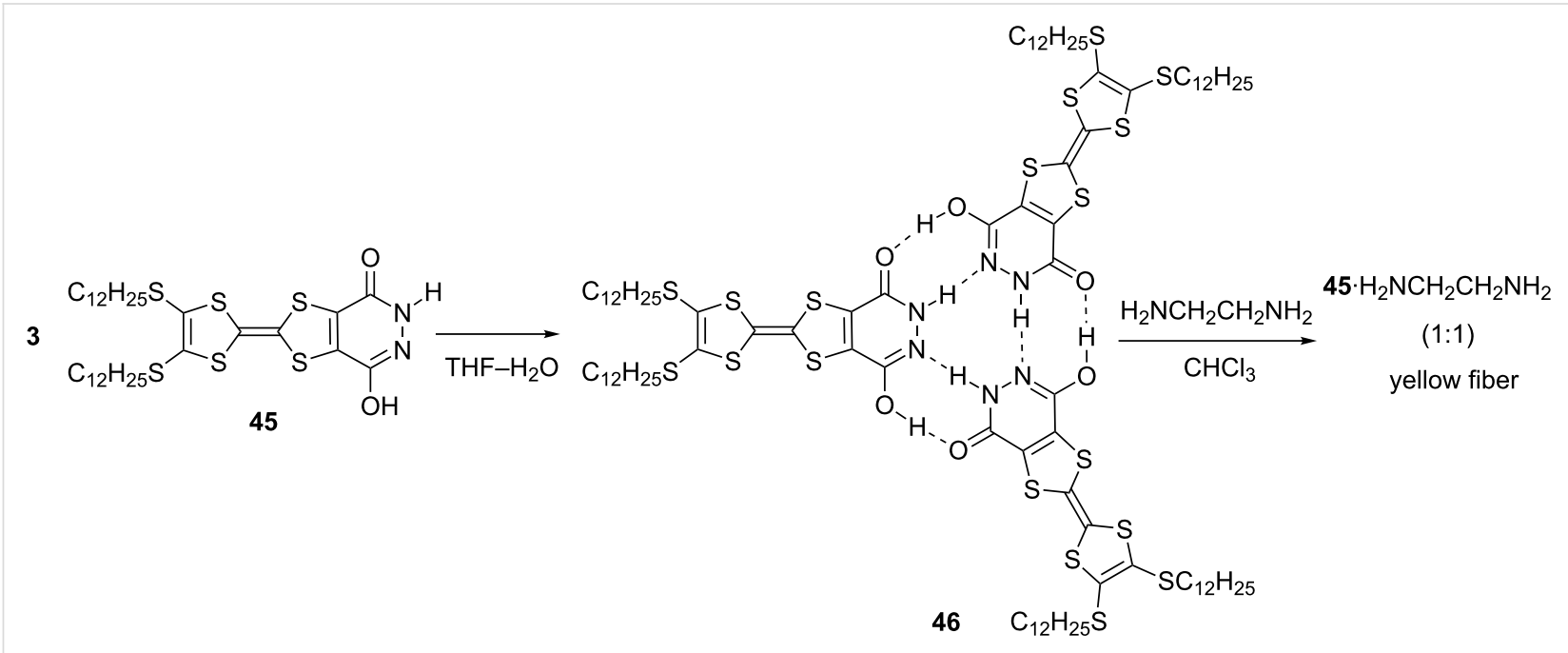

Scheme 4: Pyridazine-3,6-diol-TTF $\mathbf{4 5}$ and its trimer 46.

The monocation $\mathbf{4 8}^{\bullet+} \mathrm{ClO}_{4}{ }^{-}$easily formed a hexagonal fiber from $\mathrm{CHCl}_{3}$-hexane solution, probably owing to the strong aggregation properties and molecular shape of the stacked $\mathbf{4 8}^{\bullet+} \mathrm{ClO}_{4}^{-}$, whereas trication $\mathbf{4 8}^{3+}\left(\mathrm{ClO}_{4}{ }^{-}\right)_{3}$ produced a nanopar- ticle having a low internal regularity, presumably owing to the strong intermolecular $\mathrm{TTF}^{\bullet+}-\mathrm{TTF}^{\bullet+}$ interaction of $\mathbf{4 8}^{3+}$. A cast film of $\mathbf{4 8}^{\cdot+} \mathrm{ClO}_{4}{ }^{-}$shows a lamellar structure vertical to the substrate in a similar manner to the neutral $\mathbf{4 8}$ (Figure 17c). Inter- 


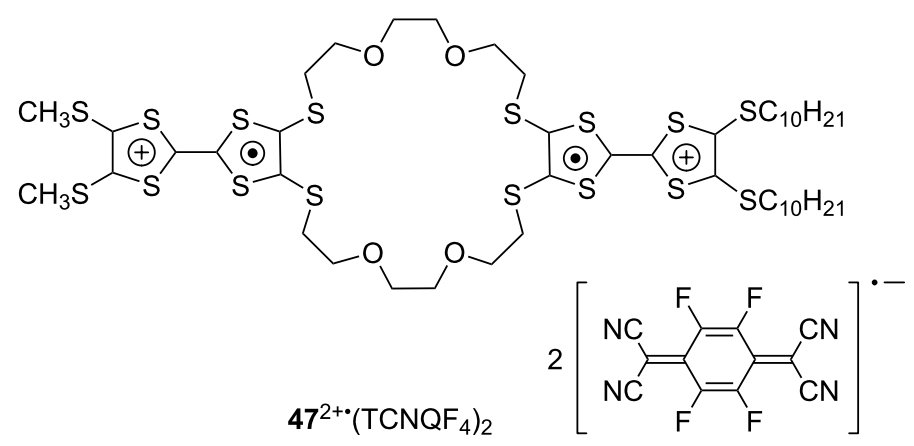

Figure 16: CT-complex of 47 with $\mathrm{TCNQF}_{4}$.

(a)

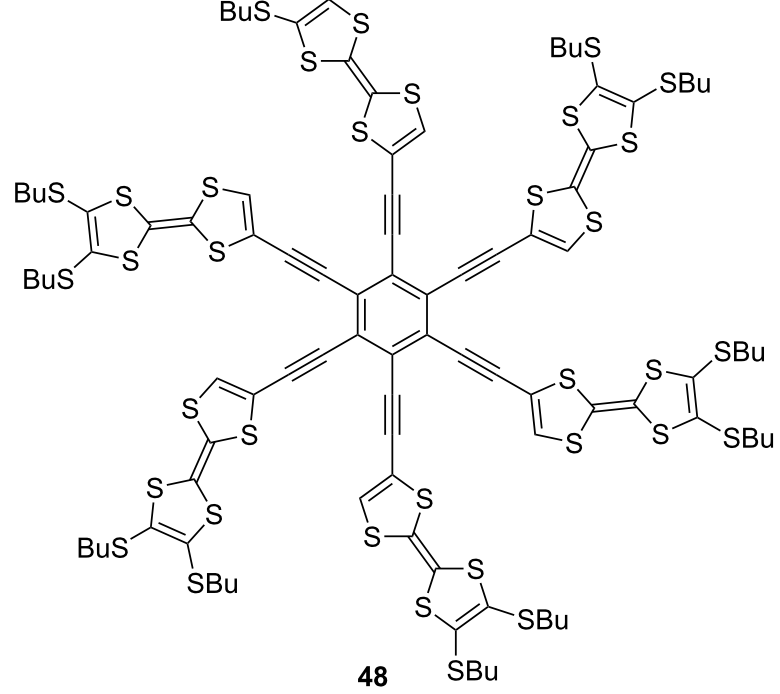

(b)

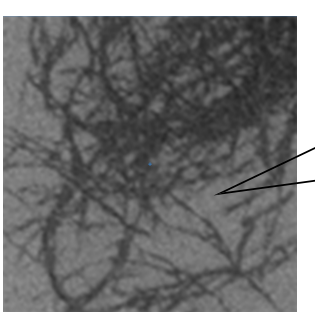

(c)

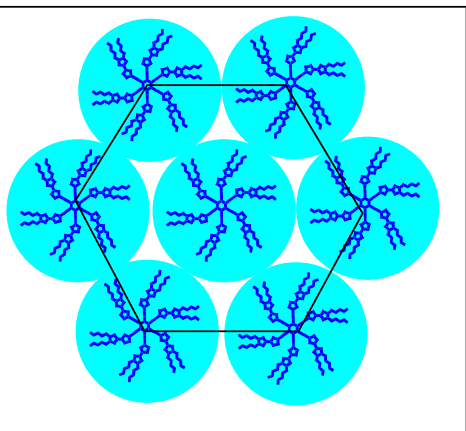

hexagonal fiber
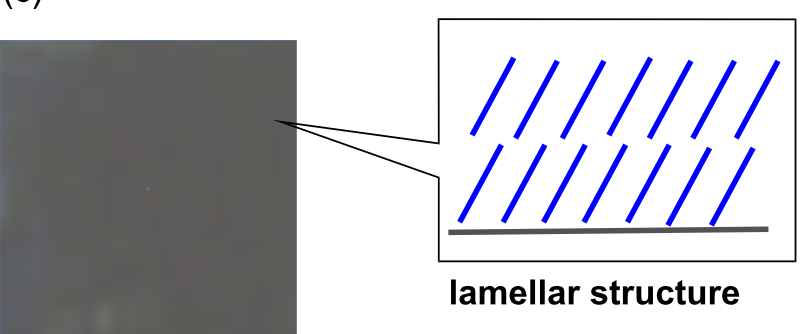

lamellar structure

Figure 17: (a) Star-shaped TTF hexamer 48. (b) Optical image of $\mathbf{4 8}$ fiber with a hexagonal structure. (c) Optical image of $\mathbf{4 8}$ film with a lamellar structure. Adapted with permission from [22]. Copyright 2007 American Chemical Society.

estingly, the structural difference between nanofiber and film of $\mathbf{4 8}^{\bullet+} \mathrm{ClO}_{4}{ }^{-}$leads to the different electric conductivities of wires $\left(\sigma_{\mathrm{rt}}=1.1 \times 10^{-3} \mathrm{~S} \mathrm{~cm}^{-1}\right)$ and film $\left(\sigma_{\mathrm{rt}}=3.1 \times 10^{-5} \mathrm{~S} \mathrm{~cm}^{-1}\right)$ depending on their stacking structures.

Cation radicals of pyrrole-fused TTF trimer 38 also formed conducting nanostructures when a $\mathrm{CH}_{2} \mathrm{Cl}_{2}$ solution of $\mathbf{3 8}^{1.5(\cdot+)}$ was mixed with an excess amount of hexane. The XRD pattern of the fiber $\mathbf{3 8}^{1.5(\cdot+)}$ is composed of a lamellar structure different from the neutral $\mathbf{3 8}$ fiber and an exhibited electric conductivity of $\sigma_{\mathrm{rt}}=2.9 \times 10^{-4} \mathrm{~S} \mathrm{~cm}^{-1}$. The lower conductivity of the fiber $\mathbf{3 8}^{1.5(\cdot+)}$ as compared to the doped $\mathbf{3 8}$ fiber $\left(\sigma_{\mathrm{rt}}=1.9 \times 10^{-2} \mathrm{~S} \mathrm{~cm}^{-1}\right)$ may be due to the difference in their internal structures.

\section{Conclusion}

The construction of nanoobjects based on the self-assembly of TTFs were rapidly advanced, and a large number of functional properties such as electronic, magnetic, and optical properties were recently reported. Based on these developments of nanoscience, the construction of conducting nanoobjects has also been investigated to realize electrochemically-driven conformational control, redox-controlled gelation processes, redox switches, and molecular sensors. Furthermore, semiconductive 
fibers and rods of TTFs can be utilized for nanosized electric wires and wirings in nanoelectronics. The next key innovation in TTF-based nanoobjects is the fulfillment of nanofiber and nanorod with metallic conductivity and superconductivity. To achieve a high electric conductivity, further knowledge is necessary to fabricate a closely stacked ionic state with unfilled bands. If these innovative systems can be implemented, conducting nanoobjects find functions in a variety of mass use devices.

\section{Supporting Information}

\section{Supporting Information File 1}

Determination of association constants $\left(K_{2}\right)$ of $\mathbf{2 3}$ by NMR and cyclic voltammetry analysis of $\mathbf{2 3}$.

[http://www.beilstein-journals.org/bjoc/content/ supplementary/1860-5397-11-175-S1.pdf]

\section{Acknowledgements}

This work was partly supported by a Grant-in-Aid for Scientific Research from JSPS and by Strategic Japanese-German Cooperative Program of JST (Japan Science and Technology Corporation). We thank Prof. Tohru Nishinaga (Tokyo Metropolitan University) and Prof. Masayoshi Takase (Ehime University) for their helpful assistance.

\section{References}

1. Batail, P. Chem. Rev. 2004, 104, 4887-4890. doi:10.1021/cr040697x

2. Yamada, Y.; Sugimoto, T. TTF Chemistry. Fundamentals and Applications of Tetrathiafulvalene; KODANSHA-Springer: New York, NY, U.S.A., 2004.

3. Ishiguro, T.; Yamaji, K.; Saito, G. Organic Superconductors, 2nd ed.; Springer Series in Solid-State Sciences, Vol. 88; Springer: Berlin, Germany, 1998. doi:10.1007/978-3-642-58262-2

4. Saito, G.; Yoshida, Y. Bull. Chem. Soc. Jpn. 2007, 80, 1-137. doi:10.1246/bcsj.80.1

5. Desiraju, G. R. Angew. Chem., Int. Ed. Engl. 1995, 34, 2311-2327. doi:10.1002/anie.199523111

6. Lehn, J.-M. Science 2002, 295, 2400-2403. doi:10.1126/science.1071063

7. Hoeben, F. J. M.; Jonkeijm, P.; Meijer, E. W.; Schenning, A. P. H. J. Chem. Rev. 2005, 105, 1491-1546. doi:10.1021/cr030070z

8. Whitesides, G. M.; Grzybowski, B. Science 2002, 295, 2418-2421. doi:10.1126/science.1070821

9. Nayak, S.; Lyon, L. A. Angew. Chem., Int. Ed. 2005, 44, 7686-7708. doi:10.1002/anie.200501321

10. Gomar-Nadal, E.; Puigmartí-Luis, J.; Amabilino, D. B. Chem. Soc. Rev. 2008, 37, 490-504. doi:10.1039/B703825A

11. Li, C.; Bai, H.; Shi, G. Chem. Soc. Rev. 2009, 38, 2397-2409. doi:10.1039/b816681c

12. Bryce, M. R.; Marshallsay, G. J.; Moore, A. J. J. Org. Chem. 1992, 57, 4859-4862. doi:10.1021/jo00044a020

13. Formigué, M.; Johannsen, I.; Boubekeur, K.; Nelson, C.; Batail, P. J. Am. Chem. Soc. 1993, 115, 3752-3759. doi:10.1021/ja00062a047
14. Iyoda, M.; Fukuda, M.; Yoshida, M.; Sasaki, S. Synth. Met. 1995, 70 , 1171-1172. doi:10.1016/0379-6779(94)02806-A

15. lyoda, M.; Fukuda, M.; Yoshida, M.; Sasaki, S. Chem. Lett. 1994, 23, 2369-2372. doi:10.1246/cl.1994.2369

16. González, A.; Segura, J. K.; Martín, N. Tetrahedron Lett. 2000, 41, 3083-3086. doi:10.1016/S0040-4039(00)00344-0

17. Kanibolotsky, A.; Roquet, S.; Cariou, M.; Leriche, P.; Turrin, C.-O.; de Bettingnies, R.; Caminade, A.-M.; Majoral, J.-P.; Khodorkovsky, V.; Gorgues, A. Org. Lett. 2004, 6, 2109-2112. doi:10.1021/ol049648x

18. Hasegawa, M.; Takano, J.-i.; Enozawa, H.; Kuwatani, Y.; lyoda, M. Tetrahedron Lett. 2004, 45, 4109-4112. doi:10.1016/j.tetlet.2004.03.150

19. Jia, H.-P.; Liu, S.-X.; Sanguine, L.; Levillain, E.; Decurtins, S. J. Org. Chem. 2009, 74, 5727-5729. doi:10.1021/j0901054b

20. Hara, K.; Hasegawa, M.; Kuwatani, Y.; Enozawa, H.; lyoda, M. Heterocycles 2010, 80, 909-915. doi:10.3987/COM-09-S(S)122

21. Pop, F.; Melan, C.; Danila, I.; Linares, M.; Beljonne, D.; Amabilino, D. B.; Avarvari, N. Chem. - Eur. J. 2014, 20, 17443-17453. doi:10.1002/chem.201404753

22. Hasegawa, M.; Enozawa, H.; Kawabata, Y.; lyoda, M. J. Am. Chem. Soc. 2007, 129, 3072-3073. doi:10.1021/ja069025+

23. Takase, M.; Yoshida, N.; Nishinaga, T.; lyoda, M. Org. Lett. 2011, 13, 3896-3899. doi:10.1021/ol2014279

24. Jeppesen, J. O.; Nielsen, M. B.; Becher, J. Chem. Rev. 2004, 104, 5115-5131. doi:10.1021/cr030630u

25. lyoda, M.; Hasegawa, M.; Miyake, Y. Chem. Rev. 2004, 104, 5085-5113. doi:10.1021/cr030651o

26. Hasegawa, M.; lyoda, M. Chem. Soc. Rev. 2010, 39, 2420-2427. doi:10.1039/b909347h

27. Canevet, D.; Sallé, M.; Zhang, G.; Zhang, D.; Zhu, D. Chem. Commun. 2009, 2245-2269. doi:10.1039/b818607n

28. Pérez, E. M.; Illescas, B. M.; Herranz, M. Á.; Martín, N. New J. Chem. 2009, 33, 228-234. doi:10.1039/B816272G

29. Brunetti, F. G.; López, J. L.; Atienza, C.; Martín, N. J. Mater. Chem. 2012, 22, 4188-4205. doi:10.1039/c2jm15710a

30. Christensen, C. A.; Bryce, M. R.; Batsanov, A. S.; Becher, J. Chem. Commun. 2000, 331-332. doi:10.1039/A909882H

31. Christensen, C. A.; Bryce, M. R.; Becher, J. Synthesis 2000, 1695-1704. doi:10.1055/s-2000-8203

32. Zou, L.; Xu, W.; Shao, X.; Zhang, D.; Wang, Q.; Zhu, D. Org. Biomol. Chem. 2003, 1, 2157-2159. doi:10.1039/b301587d

33. Le Derf, F.; Levillain, E.; Trippé, G.; Gorgues, A.; Sallé, M.; Sebastían, R.-M.; Caminade, A.-M.; Majoral, J.-P. Angew. Chem., Int. Ed. 2001, 40, 224-227. doi:10.1002/1521-3773(20010105)40:1<224::AID-ANIE224>3.0.CO;20

34. Kreher, D.; Cariou, M.; Liu, S.-G.; Levillain, E.; Veciana, J.; Rovira, C.; Gorgues, A.; Hudhomme, P. J. Mater. Chem. 2002, 12, 2137-2159. doi:10.1039/b201695h

35. Mas-Torrent, M.; Rodrígues-Mias, R. A.; Solà, M.; Molins, M. A.; Pons, M.; Vidal-Gancedo, J.; Veciana, J.; Rovira, C. J. Org. Chem. 2002, 67, 566-575. doi:10.1021/jo010748f

36. Bras, Y. L.; Sallé, M.; Leriche, P.; Mingotaud, C.; Richomme, P.; Møller, J. J. Mater. Chem. 1997, 7, 2393-2396. doi:10.1039/a704005i

37. Becher, J.; Brimert, T.; Jeppesen, J. O.; Pedersen, J. Z.; Zubarev, R.; Bjørnholm, T.; Reitzel, N.; Jensen, T. R.; Kjaer, K.; Levillain, E. Angew. Chem., Int. Ed. 2001, 40, 2497-2500. doi:10.1002/1521-3773(20010702)40:13<2497::AID-ANIE2497>3.0.CO ;2-F 
38. Cook, M. J.; Cooke, G.; Jafari-Fini, A. Chem. Commun. 1996, 1925. doi:10.1039/CC9960001925

39. Farren, C.; Christensen, C. A.; FitzGerald, S.; Bryce, M. R.; Beeby, A. J. Org. Chem. 2002, 67, 9130. doi:10.1021/jo020340y

40. Sly, J.; Kasák, P.; Gomar-Nadal, E.; Rovira, C.; Górriz, L.; Thordardarson, P.; Amabilino, D. B.; Rowan, A. E.; Nolte, R. J. M. Chem. Commun. 2005, 1255-1257. doi:10.1039/b416034g

41. Nielsen, K. A.; Cho, W.-S.; Jeppesen, J. O.; Lynch, V. M.; Becher, J.; Sessler, J. L. J. Am. Chem. Soc. 2004, 126, 16296-16297. doi:10.1021/ja044664a

42. Nielsen, K. A.; Bähring, S.; Jeppesen, J. O. Chem. - Eur. J. 2011, 17, 11001-11007. doi:10.1002/chem.201101266

43. Davis, C. M.; Lim, J. M.; Larsen, K. R.; Kim, D. S.; Sung, Y. M.; Lyons, D. M.; Lynch, V. M.; Nielsen, K. A.; Jeppesen, J. O.; Kim, D.; Park, J. S.; Sessler, J. L. J. Am. Chem. Soc. 2014, 136, 10410-10417. doi:10.1021/ja504077f

44. Pérez, E. M.; Sierra, M.; Sánchez, L.; Torres, M. R.; Viruela, R.; Viruela, P. M.; Ortí, E.; Martín, N. Angew. Chem., Int. Ed. 2007, 46, 1847-1851. doi:10.1002/anie.200604327

45. Sugimoto, T.; Awaji, H.; Misaki, Y.; Yoshida, Z.; Kai, Y.; Nakagawa, H.; Kasai, N. J. Am. Chem. Soc. 1985, 107, 5792-5793. doi:10.1021/ja00306a030

46. Sugimoto, T.; Misaki, Y.; Arai, Y.; Yamamoto, Y.; Yoshida, Z.; Kai, Y.; Kasai, N. J. Am. Chem. Soc. 1988, 110, 628-629. doi:10.1021/ja00210a069

47. Sugimoto, T.; Misaki, Y.; Kajita, T.; Yoshida, Z.; Kai, Y.; Kasai, N. J. Am. Chem. Soc. 1987, 109, 4106-4107. doi:10.1021/ja00247a042

48. Warman, J. M.; de Haas, M. P.; Dicker, G.; Grozema, F. C.; Piris, J.; Debije, M. G. Chem. Mater. 2004, 16, 4600-4609. doi:10.1021/cm049577w

49. Kroeze, J. E.; Savenije, T. J.; Vermeulen, M. J. W.; Warman, J. M. J. Phys. Chem. B 2003, 107, 7696-7705. doi:10.1021/jp0217738

50. Kostecki, R.; Schnyder, B.; Alliata, D.; Song, X.; Kinoshita, K.; Kötz, R. Thin Solid Films 2001, 396, 36-43. doi:10.1016/S0040-6090(01)01185-3

51. Müllen, K.; Rabe, J. P. Acc. Chem. Res. 2008, 41, 511-520. doi:10.1021/ar7001446

52. Joergensen, M.; Bechgaard, K.; Bjoernholm, T.; Sommer-Larsen, P.; Hansen, L. G.; Schaumburg, K. J. Org. Chem. 1994, 59, 5877-5882. doi:10.1021/jo00099a012

53. Le Gall, T.; Pearson, C.; Bryce, M. R.; Petty, M. C.; Dahlgaard, H.; Becher, J. Eur. J. Org. Chem. 2003, 3562-3568. doi:10.1002/ejoc.200300286

54. Kitamura, T.; Nakaso, S.; Mizoshita, N.; Tochigi, Y.; Shimomura, T.; Moriyama, M.; Ito, K.; Kato, T. J. Am. Chem. Soc. 2005, 127, 14769-14775. doi:10.1021/ja053496z

55. Kitahara, T.; Shirakawa, M.; Kawano, S.-i.; Beginn, U.; Fujita, N.; Shinkai, S. J. Am. Chem. Soc. 2005, 127, 14980-14981. doi:10.1021/ja0552038

56. Wang, C.; Zhang, D.; Zhu, D. J. Am. Chem. Soc. 2005, 127, 16372-16373. doi:10.1021/ja055800u

57. Inokuchi, H.; Saito, G.; Seki, K.; Wu, P.; Tanf, T. B.; Mori, T.; Imaeda, K.; Enoki, T.; Higuchi, Y.; Inaka, K.; Yasuoka, N. Chem. Lett 1986, 15, 1263-1266. doi:10.1246/cl.1986.1263

58. Honna, Y.; Isomura, E.; Enozawa, H.; Hasegawa, M.; Takase, M.; Nishinaga, T.; lyoda, M. Tetrahedron Lett. 2010, 51, 679-682. doi:10.1016/j.tetlet.2009.11.106

59. Iyoda, M.; Hasegawa, M.; Takano, J.-i.; Hara, K.; Kuwatani, Y. Chem. Lett. 2002, 32, 590-591. doi:10.1246/cl.2002.590
60. Iyoda, M.; Kuwatani, Y.; Ueno, U.; Oda, M. Chem. Commun. 1992, 158-159. doi:10.1039/c39920000158

61. Rosokha, S. V.; Kochi, J. K. J. Am. Chem. Soc. 2007, 129, 828-838. doi:10.1021/ja064166x

62. Benniston, A. C. Chem. Soc. Rev. 2004, 33, 573-578. doi:10.1039/B309963F

63. Wouters, D.; Schubert, U. S. Angew. Chem., Int. Ed. 2004, 43, 2480-2495. doi:10.1002/anie.200300609

64. Wassel, R. A.; Gorman, C. B. Angew. Chem., Int. Ed. 2004, 43, 5120-5123. doi:10.1002/anie.200301735

65. Palermo, V.; Samorì, P. Angew. Chem., Int. Ed. 2007, 46, 4428-4432. doi:10.1002/anie.200700416

66. Enozawa, H.; Hasegawa, M.; Takamatsu, D.; Fukui, K.-i.; Iyoda, M. Org. Lett. 2006, 8, 1917-1920. doi:10.1021/ol0605530

67. Enozawa, H.; Hasegawa, M.; Isomura, E.; Nishinaga, T.; Kato, T.; Yamato, M.; Kimura, T.; lyoda, M. ChemPhysChem 2009, 10 , 2607-2611. doi:10.1002/cphc.200900545

68. Enozawa, H.; Takahashi, T.; Nishinaga, T.; Kato, T.; Hasegawa, M.; lyoda, M. Bull. Chem. Soc. Jpn. 2012, 85, 1120-1137. doi:10.1246/bcsj.20120135

69. Hara, K.; Hasegawa, M.; Kuwatani, Y.; Enozawa, H.; Iyoda, M. Chem. Commun. 2004, 2042-2043. doi:10.1039/b407200f

70. Lincke, K.; Frellsen, A. F.; Parker, C. R.; Bond, A. D.; Hammerich, O.; Nielsen, M. B. Angew. Chem., Int. Ed. 2012, 51, 6099-6102. doi:10.1002/anie.201202324

71. Hanai, Y.; Rahman, M. J.; Yamakawa, J.; Takase, M.; Nishinaga, T.; Hasegawa, M.; Kamada, K.; lyoda, M. Chem. - Asian J. 2011, 6, 2940-2945.

72. Andersson, A. S.; Kilså, K.; Hassenkam, T.; Gisselbrecht, J.-P.; Boudon, C.; Gross, M.; Nielsen, M. B.; Diederich, F. Chem. - Eur. J. 2006, 12, 8451-8459. doi:10.1002/chem.200600986

73. Hasegawa, M.; Daigoku, K.; Hashimoto, K.; Nishikawa, H.; lyoda, M. Bull. Chem. Soc. Jpn. 2012, 85, 51-60. doi:10.1246/bcsj.20110224

74. Martin, R. B. Chem. Rev. 1996, 96, 3043-3064. doi:10.1021/cr960037v

75. Takase, M.; Yoshida, N.; Narita, T.; Fujio, F.; Nishinaga, T.; lyoda, M. RSC Adv. 2012, 2, 3221-3224. doi:10.1039/c2ra00035k

76. Inoue, R.; Hasegawa, M.; Mazaki, Y. Chem. Lett. 2015, 44, 448-450. doi:10.1246/cl.141165

77. Nalluri, S. K. M.; Shivarova, N.; Kanibolotsky, A. L.; Zelzer, M.; Gupta, S.; Frederix, P. W. J. M.; Skabara, P. J.; Gleskova, H.; Ulijn, R. V. Langmuir 2014, 30, 12429-12437. doi:10.1021/la503459y

78. Tatewaki, Y.; Hatanaka, T.; Tsunashima, R.; Nakamura, T.; Kimura, M.; Shirai, H. Chem. - Asian J. 2009, 4, 1474-1479. doi:10.1002/asia.200900044

79. Tanaka, K.; Kunita, T.; Ishiguro, F.; Naka, K.; Chujo, Y. Langmuir 2009, 25, 6929-6933. doi:10.1021/la900219b

80. Ahn, S.; Kim, Y.; Beak, S.; Ishimoto, S.; Enozawa, H.; Isomura, E.; Hasegawa, M.; Iyoda, M.; Park, Y. J. Mater. Chem. 2010, 20, 10817-10823. doi:10.1039/c0jm02628j

81. Tanaka, K.; Matsumoto, T.; Ishiguro, F.; Chujo, Y. J. Mater. Chem. 2011, 21, 9603-9607. doi:10.1039/c1jm11161b

82. Jain, A.; Rao, K. V.; Mogera, U.; Sagade, A. A.; George, S. J. Chem. - Eur. J. 2011, 17, 12355-12361. doi:10.1002/chem.201101813

83. Akutagawa, T.; Ohta, T.; Hasegawa, T.; Nakamura, T.; Christensen, C. A.; Becher, J. Proc. Natl. Acad. Sci. U. S. A. 2002, 99, 5028-5033. doi:10.1073/pnas.082644299

84. Akutagawa, T.; Kakiuchi, K.; Hasegawa, T.; Noro, S.-i.; Nakamura, T.; Hasegawa, H.; Mashiko, S.; Becher, J. Angew. Chem., Int. Ed. 2005, 44, 7283-7287. doi:10.1002/anie.200502336 


\section{License and Terms}

This is an Open Access article under the terms of the Creative Commons Attribution License

(http://creativecommons.org/licenses/by/2.0), which permits unrestricted use, distribution, and reproduction in any medium, provided the original work is properly cited.

The license is subject to the Beilstein Journal of Organic Chemistry terms and conditions:

(http://www.beilstein-journals.org/bjoc)

The definitive version of this article is the electronic one which can be found at:

doi:10.3762/bjoc. 11.175 